\title{
Numerical analysis of the dynamic evolution of mining-induced stresses and fractures in multilayered rock strata using continuum-based discrete element methods
}

\author{
Yang $\mathrm{Ju}^{\mathrm{a}, \mathrm{b}, *}$, Yongliang Wang ${ }^{\mathrm{b}, \mathrm{c}}$, Chuanshang $\mathrm{Su}^{\mathrm{c}}$, Dongshuang Zhang ${ }^{\mathrm{d}}$, Zhangyu Ren ${ }^{\mathrm{c}}$ \\ ${ }^{a}$ State Key Laboratory for Geomechanics and Deep Underground Engineering, China University of Mining and Technology, Xuzhou 221116, China \\ ${ }^{\mathrm{b}}$ State Key Laboratory of Coal Resources and Safe Mining, China University of Mining and Technology, Beijing 100083, China \\ ${ }^{\mathrm{c}}$ School of Mechanical \& Civil Engineering, China University of Mining and Technology, Beijing 100083, China \\ ${ }^{\mathrm{d}}$ Institute of Mechanics, Chinese Academy of Sciences, Beijing 100190, China
}

\section{A R T I C L E I N F O}

\section{Keywords:}

Continuum-based discrete element method

Multilayered rock strata

Mining-induced stress evolution

Caving zone

Fracture zone

Layer separation

\begin{abstract}
A B S T R A C T
In this study, the continuum-based discrete element method (CDEM) was adopted to simulate the evolution of mining-induced stress and fracturing during roadway tunnelling and mining in multilayered heterogeneous rock strata. The CDEM integrates the finite element method (FEM) and the discrete element method (DEM) to characterize the mining-induced stress evolution, the discontinuous fractures, separations, and caving that occur in the interfaces between multilayered rock strata. The maximum tensile-stress criterion and the Mohr-Coulomb strength criterion were used to evaluate the tensile and shear failure of the material elements. The CDEM model for rock strata was constructed by employing image processing and reconstruction approaches, using the geometrical and physical parameters that were measured from a real coal mining site. The stress evolution and compression deformation of the roof and floor strata were computed to evaluate the criticality of mining-induced disasters. The constructed model was employed to simulate and analyse the immediate roof collapse, immediate floor bulges, and the compaction of the collapse blocks, as well as the large deformation, separation, and collapse between the immediate roof and the main roof during coal seam mining. It was shown that the proposed method could predict ranges for the caving zone and fracture zone in the rock roofs that were in good agreement with the observation results from the real coal mining site.
\end{abstract}

\section{Introduction}

Two main procedures and technologies are used in the entire mining process, namely forward roadway tunnelling and backward coal seam mining. ${ }^{1,2}$ However, many incidental problems are associated with this process, such as high mining-induced stresses, squeezing failure, collapse, and fractures that affect the safety and productivity of coal mining. The entire process of forward roadway tunnelling and backward coal seam mining involves some significant issues related to mining-induced stress redistribution, collapse, and fracturing in a layered coal seam reservoir under in situ stresses and dynamic mininginduced unloading effects. Roof and floor failure is an ever-present risk and therefore a major concern in underground coal mines. Major roof falls can cause fatalities, injuries, and significant economic losses. Common mining instabilities in underground coal mines include roof falls, rib falls, and longwall face falls. ${ }^{3,4}$ To gain a comprehensive understanding of the significant problems related to roof falls, underground mines selected from various major coal fields have been investigated. ${ }^{5}$ An increasing body of evidence deriving from practical treatment in the field suggests that safe mining modes and protective measures depend on the distribution of the stress field and the evolution of cracks. ${ }^{6-8}$ Predicting, controlling, and optimising tunnelling and mining efficiency is impossible if such influencing mechanisms and factors are not understood clearly and resolved satisfactorily. Obviously, such failure ultimately affects the coal production negatively.

Numerous studies have been conducted in the past to investigate roof behaviours related to coal mining activities. For instance, Chen et al. ${ }^{9}$ studied the stress change ahead of the longwall face. Seedsman ${ }^{10}$ discussed the failure mechanisms of roadways. Shepherd and Lewandowski ${ }^{11}$ reported a site monitoring case in an underground coal mine in Australia, where the roof falls were monitored during pillar extraction. Zahl et al. ${ }^{12}$ used a roof biaxial stress meter to monitor roadway roofs. Various roof fall mechanisms have been encountered in the coal mining environment that can be classified into different

\footnotetext{
* Correspondence to: China University of Mining and Technology, D11 Xueyuan Road, Beijing 100083, China.

E-mail address: juy@cumtb.edu.cn (Y. Ju).
} 
types. ${ }^{3,13}$ The process of roof rock deformation and breakage prior to and during roof failure in an actual mining environment is complex and is still being debated among researchers and mining engineers. Effectively predicting an imminent roof fall early enough for preventative actions in underground coal mines remains a major challenge.

In situ monitoring and laboratory tests have been conducted to identify the evolution of deformation, squeezing, stress, damage, and fracturing in tunnelling and mining. ${ }^{14-16}$ Large displacements that occur around tunnels and other underground openings are associated essentially with creeping. ${ }^{17,18}$ Researchers have investigated the phenomena of excavation squeezing, ${ }^{19-21}$ proposing that squeezing could be described as a reduction in the cross section of an underground opening owing to large deformation caused by the redistribution of stress. The degree of squeezing depends largely on the geological conditions, in situ stress relative to rock mass strength, groundwater flow, and pore fluid pressure. The potential of the rock mass to squeeze is related to tunnel size, excavation, support techniques, and the mining sequence adopted in the tunnelling. Limited work has been carried out on the squeezing of underground coal mine roadways. ${ }^{22,23}$ In practice, coal mine roadways, particularly for deep coal mines, suffer from a high degree of squeezing owing to high mining-induced stress. Therefore, it is necessary to probe the stress field and the fracture field in tunnelling and mining, as well as their evolutionary processes. However, few measurements can indicate such mechanisms properly, as the processes and influencing mechanisms of mining-induced fracture initiation and growth are usually indistinct in such studies. ${ }^{24}$ Owing to the difficulties in detecting and defining the actual dynamic evolutionary behaviours of stresses and fractures in experimental methods, as well as in obtaining an accurate analytical solution for high mining-induced stress, numerical methods have been adopted widely as alternatives.

The traditional numerical models, such as those that employ the finite element method (FEM) have various limitations, as the meshes cannot be changed easily after model creation and require further mesh refinements ${ }^{25}$; therefore, the adaptive finite element method (AFEM) was developed for effective mesh refinement. ${ }^{26}$ The extended finite element method (XFEM) was developed to simulate multiple fractures, but the accuracy of the results still depends on the quality of mesh generation. ${ }^{27}$ Other numerical techniques that consider the initiation and propagation of fractures are being developed, such as bonded particle models (BMPs), ${ }^{28}$ the discontinuous deformation analysis (DDA) method, ${ }^{29}$ and the boundary element method (BEM). ${ }^{30}$ It should be noted that discrete element (DE) modelling does not require meshing, as it consists of discretised particles that are free to move with respect to each other. ${ }^{31}$ Numerical simulation of squeezing failure in a coal mine roadway owing to mining-induced stress has been analysed by the discrete element method (DEM). ${ }^{32}$ Software based on the DEM is being developed, such as the universal distinct element code (UDEC), ${ }^{33}$ 3D distinct element code (3DEC), ${ }^{34}$ and the particle flow code (PFC). ${ }^{35}$ We established 3D models and analysed the effects of natural microcracks on the supercritical $\mathrm{CO}_{2}$ fracture network of shale rock by using BPMs in PFC and by establishing gas flow and solid deformation coupling. ${ }^{36}$ Adopting FEM and DEM, the combined finite-discrete element method was proposed and developed to simulate fracture propagation, ${ }^{37,38}$ and the numerical techniques were developed for engineering applications, such as the progressive damage and failure processes in rock and the dynamic excavation of tunnels. ${ }^{39,40}$ The continuum-based discrete element method (CDEM) combines the accuracy of FEM stress solutions in continuum solids with the flexibility of fracture propagation in the DEM results in a coupled approach that presents a potential technique for dealing with fracturing problems. ${ }^{41-43}$ This method shows superior reliability and effectiveness for solving the problem of the stress field and fracture field. We will introduce CDEM in this paper, with FEM used to compute the stress field effectively and DEM to determine the fracture initiation and propagation behaviours in coal seam mining.

Geometrical attributes and physical parameters are crucial aspects that affect the indirect reaction under external activity. In the underground mining process, the rock mass is prone to break along inhomogeneous particles, bedding surfaces, and structural planes; therefore, it is vital to reconstructing the complex geometrical structure and material properties of the rock. Such reconstruction methods and models have emerged with time. Research has been conducted by using the digital image-processing-based FEM to study the meso-structure and meso-mechanical characteristics of the soil-rock mixture as typical inhomogeneous geomaterial forming the actual reservoir. ${ }^{44}$ We studied the crack initiation and propagation processes by using heterogeneous reconstruction models based on computed tomography (CT) as natural heterogeneous glutenites. Our findings indicated that material heterogeneity has a considerable effect on crack initiation and that crack propagation is controlled primarily by in situ stress ratios, with the reconstruction models proven to act as appropriate approaches to introduce the actual reservoir. ${ }^{42,43,45}$ Geometrical attributes and physical parameters can be extracted for field monitoring or laboratory experiments, based on image processing and reconstruction approaches. In this study, reconstruction based on the image processing method will be developed for an actual coal seam reservoir.

To represent the accurate distribution and dynamic evolution behaviours of the stress field and fracture field of the surrounding rock during coal mining, this study used the geometrical attributes and physical parameters that were extracted from the actual coal seam reservoir, based on the image processing and reconstruction approaches. The reconstructed models for forward roadway tunnelling and backward coal seam mining were analysed, and the deformation, stress field, and fracture field were characterised at different stages. The caving zone and fracture zone in the surrounding rock roof were evaluated using the proposed method.

The remainder of this paper is organised as follows. In Section 2, we describe in detail the numerical simulation using the CDEM, including the governing equations, the fracture criteria, and the coupled finite element (FE) and discrete element (DE) approach. In Section 3, we present numerical models and summarise the reconstructed layered reservoir for roadway tunnelling and coal seam mining, as well as the global procedure. The numerical results, analysis of the mining-induced stress, deformation and fracture, and the heights of the caving zone and fracture zone are outlined in Section 4. Our concluding remarks are summarised in Section 5.

\section{A continuum-based discrete element method for mining}

In this study, the advantages of FEM and DEM were combined in the CDEM algorithm, based on the coupled FE-DE algorithm for the evolution of the mining-induced stress field and fracture field. ${ }^{41-43}$ In the dynamic mining process, the $\mathrm{FE}$ algorithm for the continuum rock matrix is used to compute displacements and stresses. Subsequently, the tensile or shear failure is determined by the fracture criteria using the current stresses, and the DE algorithm for the discrete rock matrix is used to update the geometrical model by element separation. A microstructural model of rock material comprises two elements, namely block elements and jointed elements. The model is configured such that the FEM is used inside the block and the DEM is adopted for the interface. Furthermore, the strength of each element is related to its deformation modulus, and the deformation of each block element is obtained according to the state of stress and constitutive relation of the materials. Various elements of conventional FEM could be introduced flexibly to the CDEM models. This method has considerable advantage in simulating dynamic fracture processes, and it has a variety of applications related to problems associated with continuous or discontinuous deformation under dynamic or static loads.

The motion equation is the governing equation for the movement of elements and takes the deformation of elements into account. For every block within the model, certain governing equations must be satisfied. The details are introduced as follows. 


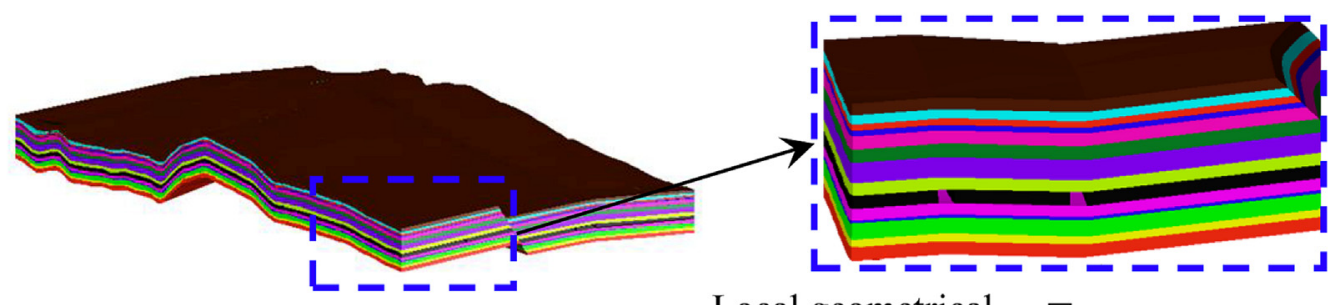

Actual layered reservoir

Local geometrical

layered reservoir

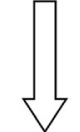

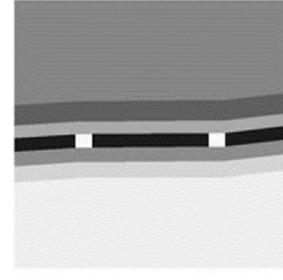

Simplified slice containing typical layers

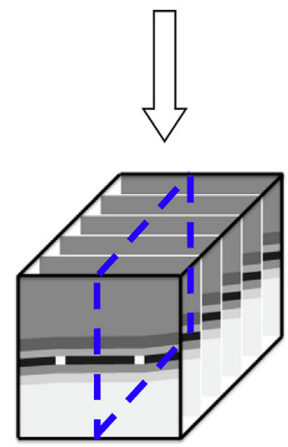

$3 \mathrm{D}$ reconstruction model by parallel slices

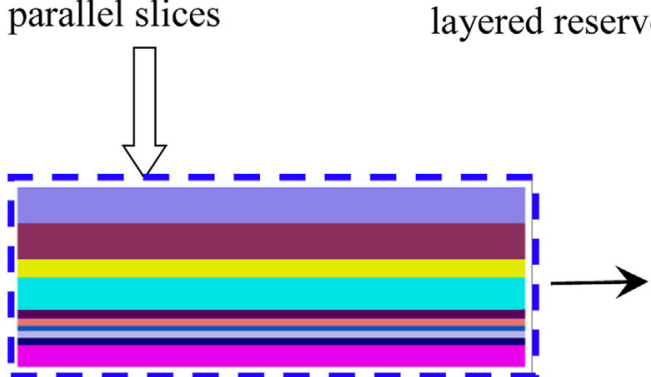

2D geometrical model of mining in sensitive reservoir slice

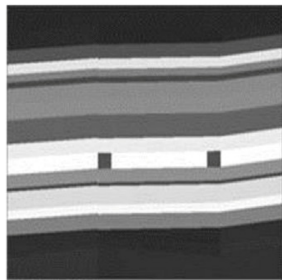

Transformed

grey slice

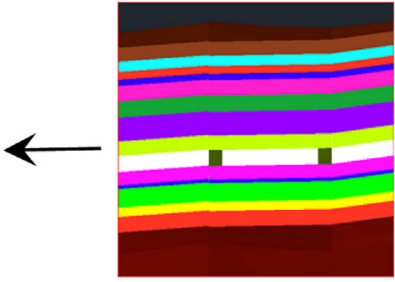

Vertical

slice

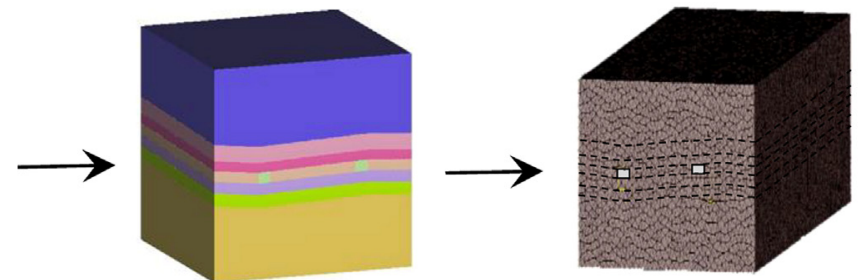

3D geometrical model of tunnelling in layered reservoir
3D numerical model with mesh of tunnelling for CDEM

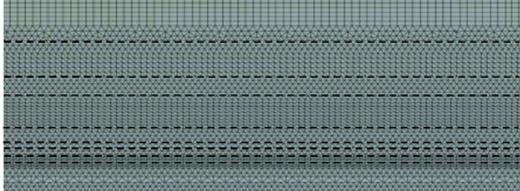

2D numerical model with mesh of mining for CDEM

Fig. 1. Procedure for reconstruction of the layered reservoir for the tunnelling model and mining model.

\subsection{Governing equations}

The mechanical equilibrium equation in Cartesian coordinates for solid deformation, considering the influence of dynamic inertia, is given as $^{41-43}$ :

$\nabla \cdot \sigma=\rho \ddot{\mathbf{u}}+c \dot{\mathbf{u}}-\mathbf{f}, \quad x, y, z \in \Omega$,

where $\mathbf{u}(x, y, z)=(u(x, y, z), v(x, y, z), w(x, y, z),)^{T}$ is the vector displacement, $\sigma$ means the stress vector, $\mathbf{f}$ stands for the body force vector, $\rho$ is the density, $C$ is the damping coefficient, $\mathbf{u}$ is the displacement vector, $\dot{\mathbf{u}}$ and $\ddot{\mathbf{u}}$ denote the velocity and acceleration vectors, respectively, in which prime denotes the derivative with respect to time $t$, and $\Omega$ is the solution domain.

The strain-displacement relationship is given as:

$\varepsilon=\frac{1}{2}\left(\nabla \mathbf{u}+(\nabla \mathbf{u})^{T}\right)$

where $\varepsilon$ is the strain vector.

The constitutive relation law is given as:

$\sigma^{e}=\mathbf{D}: \varepsilon$, 


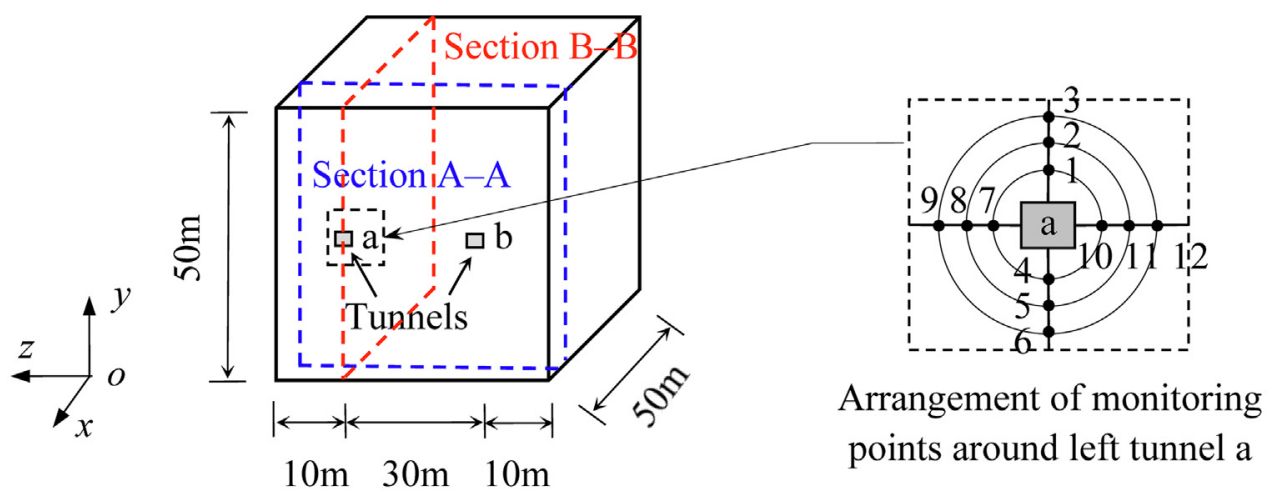

(a) 3D tunnelling model
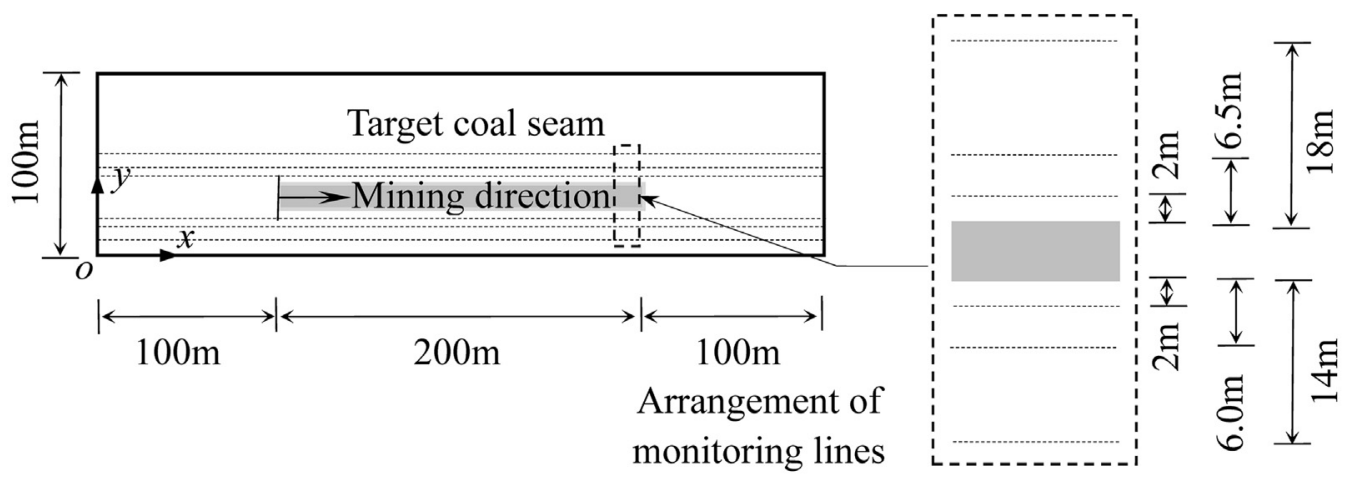

(b) 2D mining model

Fig. 2. CDEM models and monitoring points, and monitoring lines for forward tunnelling and backward mining.

Table 1

Basic mechanical parameters of the rock strata (roadway tunnelling).

\begin{tabular}{|c|c|c|c|c|c|c|c|c|c|}
\hline$n$ & Stratum & Lithology & $h_{t}(\mathrm{~m})$ & $\phi\left({ }^{\circ}\right)$ & $C(\mathrm{MPa})$ & $\bar{\sigma}_{n}(\mathrm{MPa})$ & $\rho\left(\mathrm{g} / \mathrm{cm}^{3}\right)$ & $E(\mathrm{GPa})$ & $v$ \\
\hline 1st & Main roof and above strata & Fine-grained sandstone & 18 & 28.53 & 3.10 & 2.01 & 2.86 & 20.1 & 0.27 \\
\hline 2nd & Main roof & Medium-grained sandstone & 5 & 30.39 & 2.20 & 6.67 & 2.59 & 25.78 & 0.21 \\
\hline 3rd & Immediate roof & Mudstone & 4 & 22.5 & 1.59 & 1.92 & 2.69 & 10.36 & 0.25 \\
\hline 4th & Coal seam & Coal matrix & 3 & 31.82 & 2.10 & 0.36 & 1.40 & 2.70 & 0.24 \\
\hline 5 th & Immediate floor & Siltstone & 4 & 34.17 & 2.74 & 5.21 & 2.53 & 32.1 & 0.31 \\
\hline 6th & Main floor & Mudstone & 4 & 22.5 & 1.59 & 1.92 & 2.69 & 10.36 & 0.25 \\
\hline 7th & Main floor and underlying strata & Medium-grained sandstone & 12 & 30.39 & 2.20 & 6.67 & 2.59 & 25.78 & 0.21 \\
\hline
\end{tabular}

Note: $n$ is the layer number of the stratum; $h_{t}$ is the thickness of the stratum; $E$ is the Young's modulus; $v$ is the Poisson's ratio.

Table 2

Basic mechanical parameters of the rock strata (coal seam mining).

\begin{tabular}{|c|c|c|c|c|c|c|c|c|}
\hline$n$ & Lithology & $h_{t}(\mathrm{~m})$ & $\phi\left({ }^{\circ}\right)$ & $C(\mathrm{MPa})$ & $\bar{\sigma}_{n}(\mathrm{MPa})$ & $\rho\left(\mathrm{g} / \mathrm{cm}^{3}\right)$ & $E(\mathrm{GPa})$ & $v$ \\
\hline 1st & Mudstone & 20 & 22.5 & 1.59 & 1.92 & 2.69 & 10.36 & 0.25 \\
\hline 2nd & Medium-grained sandstone & 20 & 30.39 & 2.20 & 6.67 & 2.59 & 25.78 & 0.21 \\
\hline 3rd & Mudstone & 10 & 22.5 & 1.59 & 1.92 & 2.69 & 10.36 & 0.25 \\
\hline 4th & Fine-grained sandstone & 18 & 28.53 & 3.10 & 2.01 & 2.85 & 20.1 & 0.27 \\
\hline 5th & Medium-grained sandstone & 5 & 30.39 & 2.20 & 6.67 & 2.59 & 25.78 & 0.21 \\
\hline 6th & Mudstone & 4 & 22.5 & 1.59 & 1.92 & 2.69 & 10.36 & 0.25 \\
\hline 7th & Coal matrix & 3 & 31.82 & 2.10 & 0.36 & 1.40 & 2.70 & 0.24 \\
\hline 8th & Siltstone & 4 & 34.17 & 2.74 & 5.21 & 2.53 & 32.1 & 0.31 \\
\hline 9th & Mudstone & 4 & 22.5 & 1.59 & 1.92 & 2.69 & 10.36 & 0.25 \\
\hline 10th & Medium-grained sandstone & 12 & 30.39 & 2.20 & 6.67 & 2.59 & 25.78 & 0.21 \\
\hline
\end{tabular}

where $\mathbf{D}$ is the elastic matrix.

The boundary conditions are given as:

$\mathbf{u}=\overline{\mathbf{u}}, \quad$ on $\Gamma_{u}$, $\sigma \cdot \mathbf{n}=\overline{\mathbf{t}}, \quad$ on $\quad \Gamma_{t}$,

where the displacement $\overline{\mathbf{u}}$ is prescribed on the displacement boundary $\Gamma_{u}$, and the confining stress $\overline{\mathbf{t}}$ is prescribed on the external 
Table 3

Basic mechanical parameters of the rock joints.

\begin{tabular}{|c|c|c|c|c|c|c|c|}
\hline$n$ & Lithology & $h_{t}(\mathrm{~m})$ & $K_{n}^{e}(\mathrm{GPa})$ & $K_{t}^{e}(\mathrm{GPa})$ & $\phi\left({ }^{\circ}\right)$ & $C(\mathrm{MPa})$ & $\bar{\sigma}_{n}(\mathrm{MPa})$ \\
\hline 1 st & Mudstone & 20 & 16.2 & 6.2 & 21 & 1.3 & 0.45 \\
\hline 2nd & Medium-grained sandstone & 20 & 30.2 & 10.5 & 30 & 5 & 0.6 \\
\hline 3rd & Mudstone & 10 & 16.2 & 6.2 & 21 & 1.3 & 0.45 \\
\hline 4th & Fine-grained sandstone & 18 & 30 & 10.2 & 24 & 4.05 & 0.67 \\
\hline 5 th & Medium-grained sandstone & 5 & 30.2 & 10.5 & 30 & 5 & 0.6 \\
\hline 6th & Mudstone & 4 & 16.2 & 6.2 & 21 & 1.3 & 0.45 \\
\hline 7th & Coal matrix & 3 & 8.26 & 3.21 & 18 & 0.9 & 0.21 \\
\hline 8th & Siltstone & 4 & 13.7 & 4.9 & 20 & 0.9 & 0.15 \\
\hline 9th & Mudstone & 4 & 16.2 & 6.2 & 21 & 1.3 & 0.45 \\
\hline 10th & Medium-grained sandstone & 12 & 30.2 & 10.5 & 30 & 5 & 0.6 \\
\hline
\end{tabular}

Table 4

Computed results of tunnelling model for different initial meshes.

States $\quad$ Initial mesh

Vertical stress $\sigma_{y}(\mathrm{MPa})$ in section A-A and section B-B at tunnelling distance of $35 \mathrm{~m}$

Case Ia (1,755,392 elements)

Case Ib $(1,834,215$ elements $)$
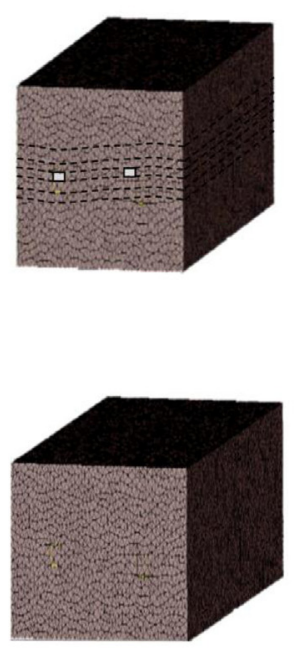
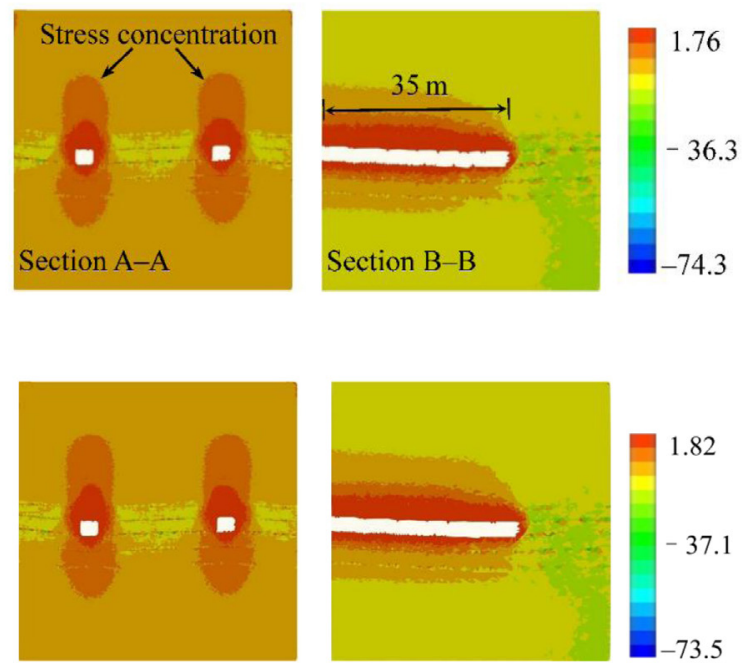

force boundary $\Gamma_{t}$.

The initial conditions are given as:

$\mathbf{u}(t=0)=\overline{\mathbf{u}}^{0}, \quad$ on $\quad \Gamma_{u}^{0}$,

$\sigma(t=0) \cdot \mathbf{n}=\overline{\mathbf{t}}^{0}, \quad$ on $\quad \Gamma_{t}^{0}$,

where the displacement $\overline{\mathbf{u}}^{0}$ is prescribed on the initial displacement boundary $\Gamma_{u}^{0}$, and the confining stress $\overline{\mathbf{t}}^{0}$ is prescribed on the initial external force boundary $\Gamma_{t}^{0}$.

\subsection{Fracture criteria}

The failure, slipping, and fracture of a solid occur in the interface between the elements. The maximum tensile-stress criterion and the Mohr-Coulomb strength criterion ${ }^{41,46-48}$ are used widely to judge the tensile and shear failure in geotechnical and rock engineering. These criteria have been used to distinguish fracture types quantificationally (e.g. tensile or shear failure). Furthermore, in some commercial numerical software, such as the universal distinct element code (UDEC), ${ }^{33}$ 3D distinct element code (3DEC), ${ }^{34}$ and the particle flow code (PFC), ${ }^{35}$ fast Lagrangian analysis of continua (FLAC), ${ }^{49}$ and realistic failure process analysis (RFPA), ${ }^{50}$ the maximum tensile-stress criterion and the Mohr-Coulomb strength criterion are used to simulate the tensile and shear failure behaviours of soil and rock. In this research, these criteria were used to determine the tensile and shear failure of the elements in the $\mathrm{CDEM}^{41-43}$ :

Tensile failure criterion : $\sigma_{n} \geq \bar{\sigma}_{n}$

Shear failure criterion : $\tau \geq \sigma_{n} \tan \phi+C$

where and $\tau$ are the normal and tangential stresses, respectively, $\bar{\sigma}_{n}$ is the tensile strength, $C$ is the cohesion, and $\varphi$ is the internal friction angle.

For implementing fracture process in the CDEM algorithm, the initial geometric domain is discrete as the FE domain and the DE domain. ${ }^{41-43}$ The contacts between the FE and DE elements are springs. The solid would rupture by separating at the node if either of the above criteria was satisfied, which means that cracks could not gain access into the elements. $\mathbf{K}^{e}=\left(K_{n}^{e}, K_{t}^{e}\right)$ is the stiffness matrix of the elements by conventional FE discretisation, the components of which can represent the normal and tangential stiffness of the spring in the CDEM. $^{41-43}$

The strategy for converting the continuous interface of the element into the discontinuous surface of the fracture is described below. The interface of the element would separate if the normal or tangential stress satisfied the fracture criteria in Eq. (6). The newly separated 
(a) $5 \mathrm{~m}$

(b) $15 \mathrm{~m}$

(c) $25 \mathrm{~m}$

(d) $35 \mathrm{~m}$
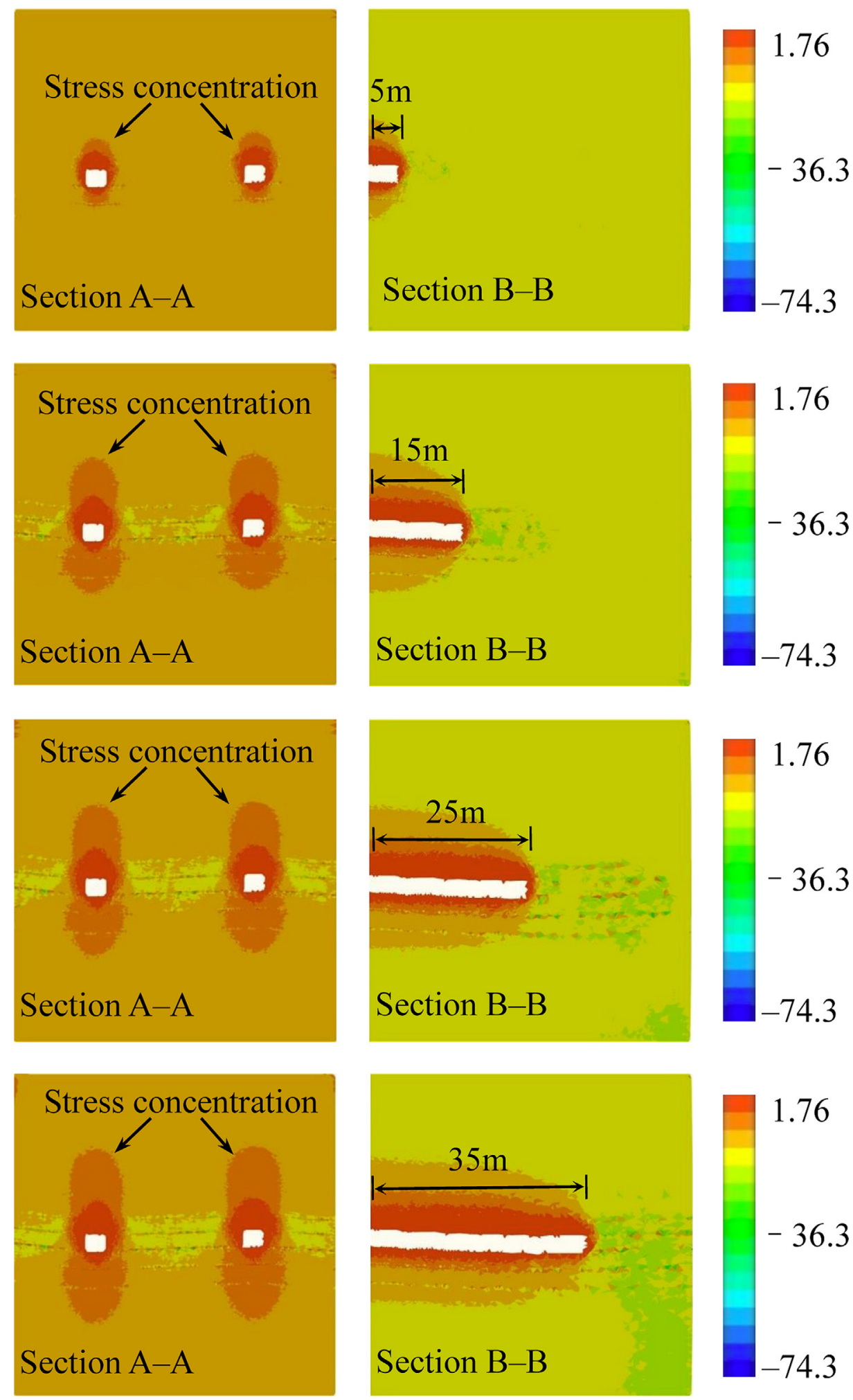

Fig. 3. Evolution of vertical stress $\sigma_{y}(\mathrm{MPa})$ in section $\mathrm{A}-\mathrm{A}$ and section B-B of the tunnelling model at different tunnelling distances.

interface of elements continues to deform because of the unloading effect, finally evolving into a typical tensile or shear fracture. The aperture of load-induced fractures is determined by the normal and tangential displacement of the separated interface caused by separated nodes, as follows:

$w=\left|\left(\mathbf{u}_{1}^{a}-\mathbf{u}_{2}^{b}\right) \cdot \mathbf{n}_{12}\right|$, where $\mathbf{u}_{1}^{a}$ and $\mathbf{u}_{2}^{b}$ are the displacement increments of separated nodes 1 and 2 of the two elements $a$ and $b$, respectively, and $\mathbf{n}_{12}$ is the normal identity vector of contact between nodes 1 and 2 .

It is noteworthy that the above fracture criteria for tensile and shear failure involve the parameters of the rock material, such as the tensile strength, cohesion, and the internal friction angle. The criteria have been used to judge the fracture imitation and propagation, which have 


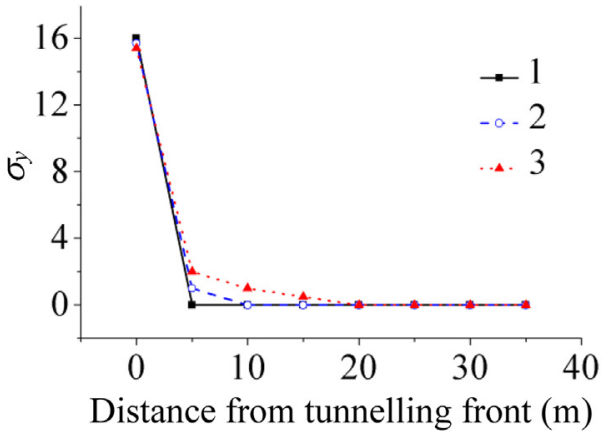

(a) Monitoring points 1-3 in rock roof

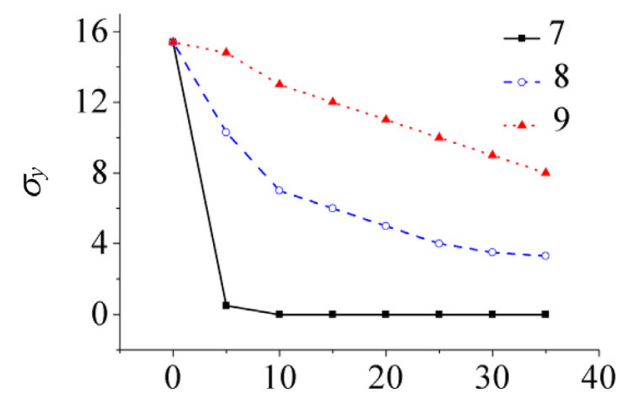

Distance from tunnelling front $(\mathrm{m})$

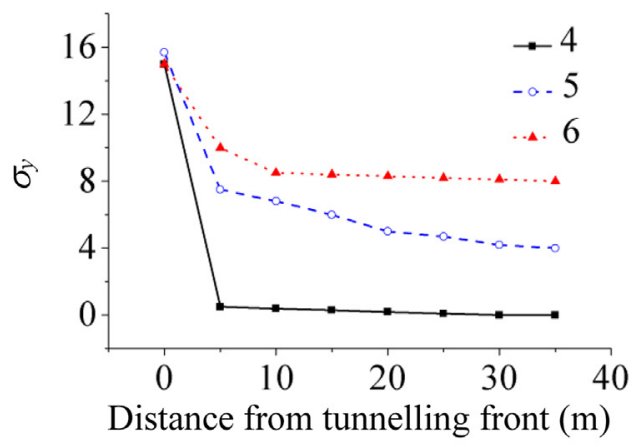

(b) Monitoring points 4-6 in rock floor

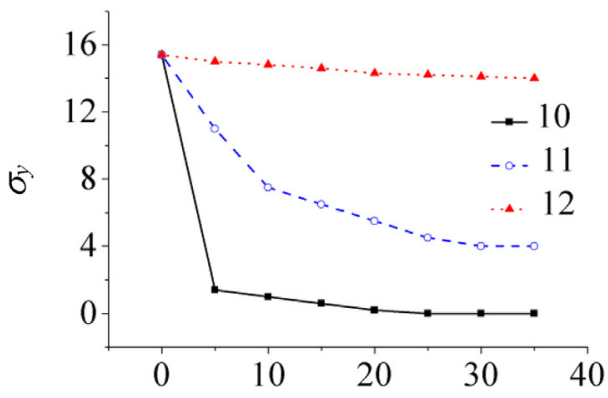

Distance from tunnelling front $(\mathrm{m})$

(c) Monitoring points 7-9 in lateral wall

(d) Monitoring points 10-12 in lateral wall

Fig. 4. Evolution of vertical stress $\sigma_{y}(\mathrm{MPa})$ of the monitoring points of the tunnelling model at different tunnelling distances.

been validated by many numerical examples, i.e. the hydraulic fracturing simulation, landslide, rock rupture, and the mining process. ${ }^{41-43,51,52}$ In addition, the failure criteria used in the proposed models are based on the strength and current stress state, rather than the energy form. The advantages of the strength criteria might well be that the tensile or shear cracks can be formed and distinguished in the simulation, ${ }^{43}$ which is crucial in some engineering processes, such as initiation, propagation, and the separation of various types of mininginduced fractures in the mining and tunnelling process.

\subsection{Coupled FE-DE approach}

To solve the governing equation of solid deformation, based on the FEM and using the variation formulation, the equilibrium equation as Eq. (1) can be transformed into the following matrix form ${ }^{41,43}$ :

$\mathbf{M}^{e} \ddot{\mathbf{D}}+\mathbf{C}^{e} \dot{\mathbf{D}}+\mathbf{K}^{e} \mathbf{D}=\mathbf{F}^{e}, \quad x, y, z \in \Omega$,

where $\mathbf{D}(t)$ is the so-called displacement vector composed by assembling the nodal displacements of all the FE elements; $\mathbf{M}^{e}, \mathbf{C}^{e}$, and $\mathbf{K}^{e}$ are the mass, damping, and stiffness matrices, respectively; $\dot{\mathbf{D}}(t)$ and $\ddot{\mathbf{D}}(t)$ denote vectors containing the nodal velocities and accelerations at time $t$, respectively; and $\mathbf{F}^{e}$ is the loading vector. $\mathbf{F}^{e}$ can be expressed as:

$\mathbf{F}^{e}=\mathbf{F}_{b}^{e}+\mathbf{F}_{s}^{e}+\mathbf{F}_{t}^{e}$,

where $\mathbf{F}_{b}^{e}$ refers to the body force; $\mathbf{F}_{s}^{e}$ represents the spring force; and $\mathbf{F}_{t}^{e}$ is the force on the traction boundary.

The CDEM employs an explicit iteration in the time domain of the calculation in order to use the dynamic relaxation method to solve the equation. In this technique, the acceleration is iterated by the central difference scheme, whereas the velocity is iterated by the unilateral difference scheme. The schemes can be written as ${ }^{41,43}$ :

$\ddot{u}_{i}^{n}=\frac{u_{i}^{n+1}-2 u_{i}^{n}+u_{i}^{n-1}}{(\Delta t)^{2}}$,
$\dot{u}_{i}^{n+1}=\frac{u_{i}^{n+1}-u_{i}^{n}}{\Delta t}$,

where, $\ddot{u}_{i}^{n}, \dot{u}_{i}^{n}$, and $u_{i}^{n}$, respectively, represent the acceleration, the velocity, and the displacement of the??th node of one element at the $n$th time step. The explicit iteration technique can be formulated from ${ }^{41,43}$ :

$\dot{u}_{i}^{n+1}=\dot{u}_{i}^{n}+\ddot{u}_{i}^{n} \Delta t$,

$u_{i}^{n+1}=u_{i}^{n}+\dot{u}_{i}^{n+1} \Delta t$.

Based on the above discrete form of governing equations and the dynamic relaxation method, the displacement was solved. Using the strain-displacement relationship as Eq. (2) and the constitutive relation law as Eq. (3), the stresses can be solved, and the normal and tangential stresses on the nodes used in Eqs. (6a) and (6b) can be transformed subsequently.

Using the conventional DEM, the techniques of fracture criteria and aperture computation of load-induced fractures were introduced in this research. The interfaces between the multilayers in both the tunnelling model and the mining model can separate through the conventional DEM once the tensile failure or shear failure criterion is satisfied. The geometric domain of the model is discrete, as the DE elements are connected by springs with normal and tangential stiffness $\mathbf{K}^{e}=\left(K_{n}^{e}, K_{t}^{e}\right)$, which would separate if the fracture criteria were satisfied. ${ }^{41-43}$

\section{Numerical models and implementation}

\subsection{Reconstruction based on image processing method}

The image processing method was used to reconstruct the coal seam using the data that were collected from natural coal mine project sites, namely the Liyazhuang Coal Mine in Shanxi Province, China. We used the actual geometric attributes and the physical parameters of the reservoir to analyse its geometric distribution and layered characteristics. 
(a) $5 \mathrm{~m}$

(b) $15 \mathrm{~m}$

(c) $25 \mathrm{~m}$

(d) $35 \mathrm{~m}$
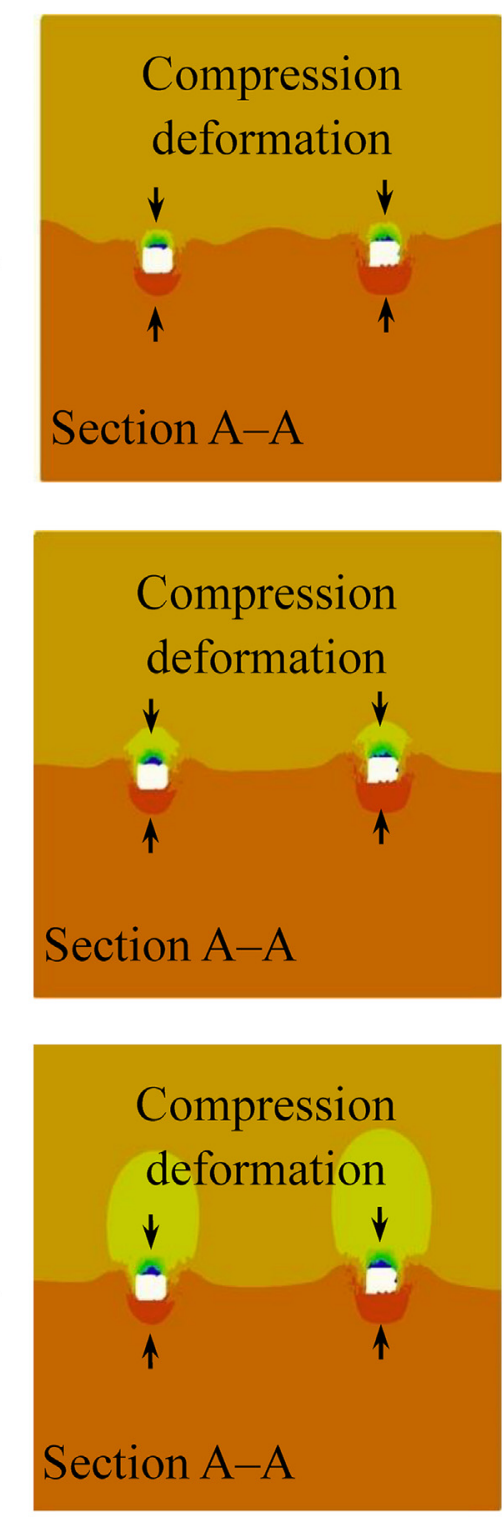
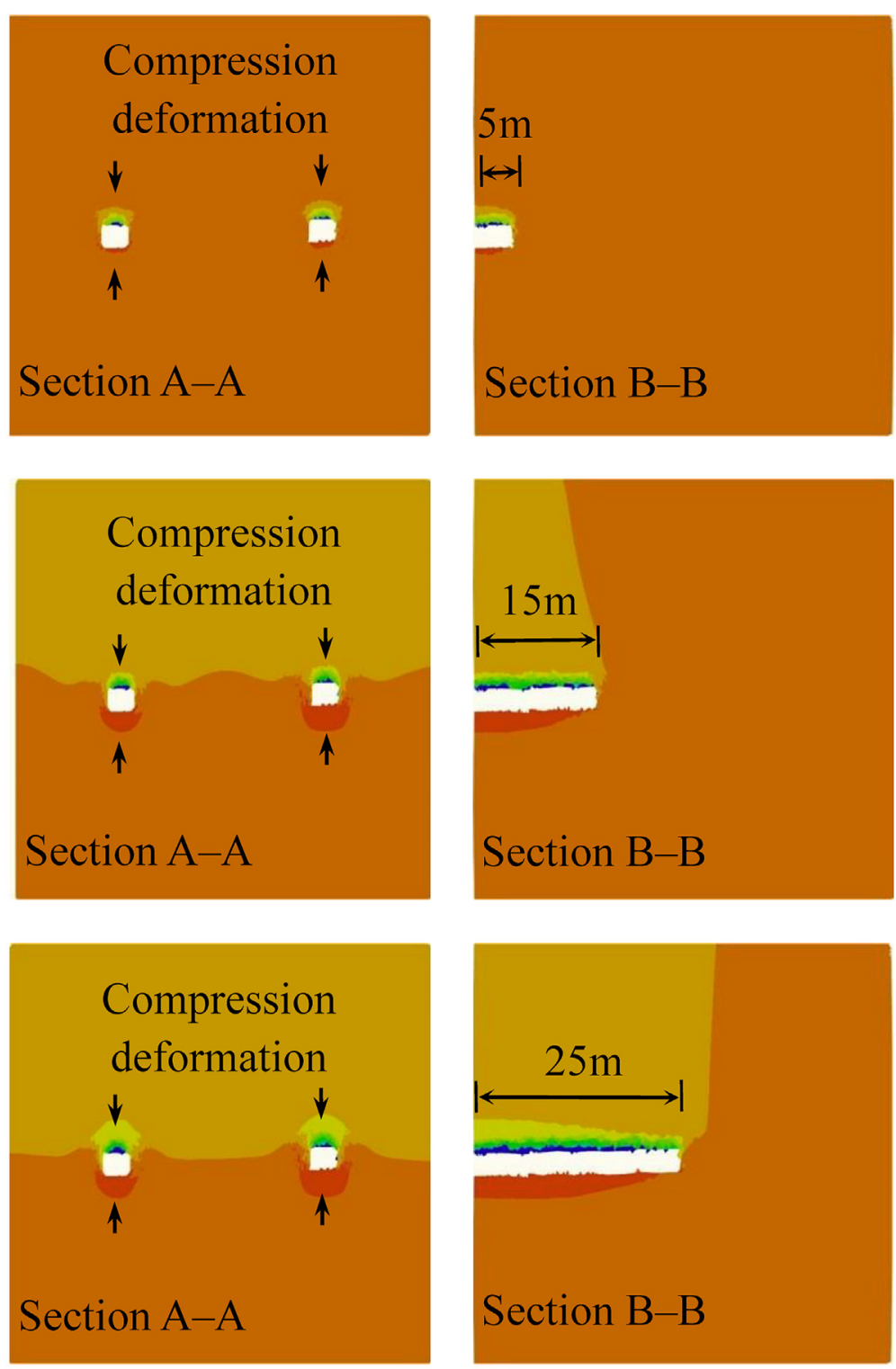
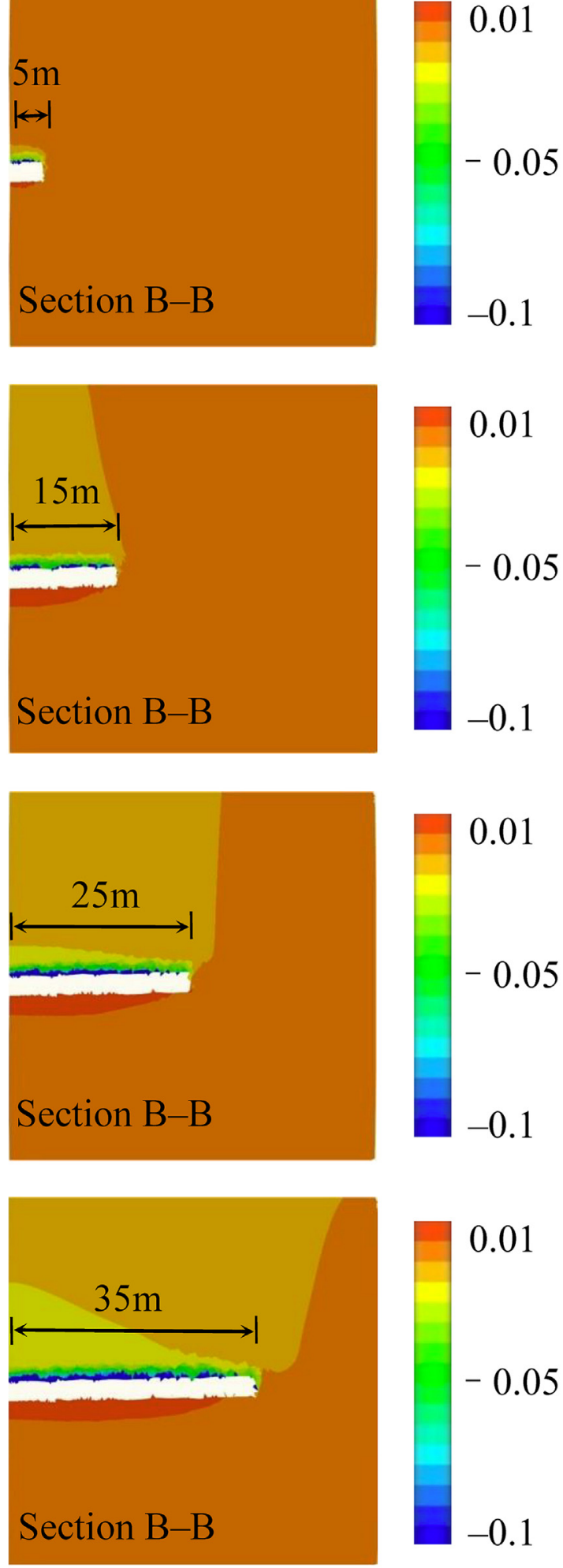

Fig. 5. Evolution of vertical displacement $u_{y}(\mathrm{~m})$ in section A-A and section B-B of the tunnelling model at different tunnelling distances.

Diagrams of the typical reconstruction procedure based on the image processing method are shown in Fig. 1. The details are as follows:

(1) Actual layered strata: a typical and representative sample of the actual layered strata from the Liyazhuang Coal Mine was selected for the research, of which the geometrical size and materials were preserved and presented;
(2) Local geometrical layered strata: the local and regular strata suitable for coal seam mining were selected for the simulation;

(3) Vertical slice: various vertical slices containing the layer information from the actual 3D layered reservoir were chosen for the reconstruction;

(4) Transformed grey slice: the vertical slices were transformed into grey slices for consideration for computer computation; 


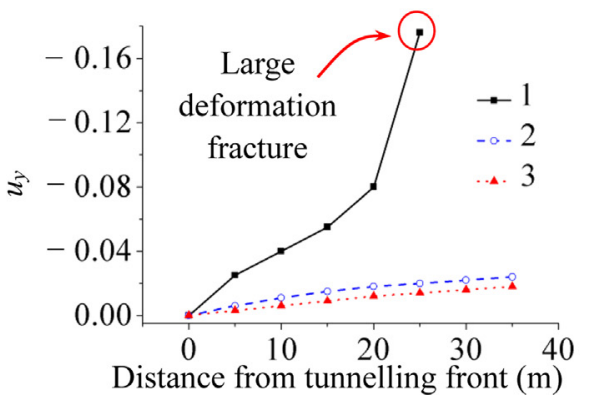

(a) Monitoring points 1-3

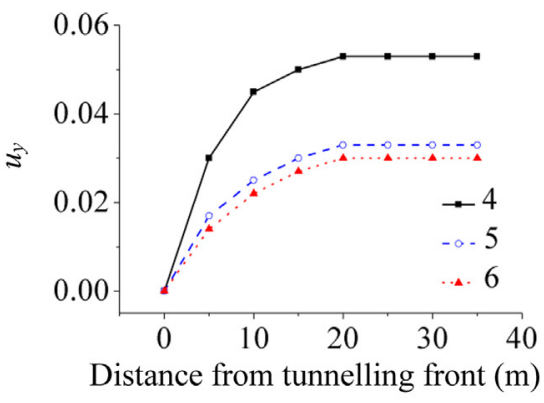

(b) Monitoring points 4-6

Fig. 6. Evolution of vertical displacement $u_{y}(\mathrm{~m})$ of the monitoring points of the tunnelling model at different tunnelling distances.

(5) Simplified slice containing typical layers: as some layers are situated at a considerable distance from the coal seam reservoir and, in an effort to simplify the modelling and computation, various distant layers were homogenised as the same layer, but the typical layers near the coal seam were retained;

(6) 3D reconstruction model by parallel slices: the 3D model could be reconstructed by using numerous parallel slices sequentially;

(7) 3D geometrical model of tunnelling in layered reservoir: interpolation was used to obtain continuous filling between the grey images of the parallel layers to form a 3D reconstruction model that is approximately equivalent to the layered reservoir. In this step, the coordinates, material properties, and the internal nodes of the reconstruction model were provided simultaneously via the MIMICS ${ }^{\circ}$ program (http://www.materialise.com/);

(8) 3D numerical model with mesh of tunnelling for CDEM: for the 3D geometrical model, the continuous model was discretised into the numerical model, which was meshed to obtain the 3D numerical model of tunnelling for CDEM. In detail, the geometrical model was introduced into the ANSYS ${ }^{\circ}$ software (http://www.ansys. $\mathrm{com} /$ ) to create a mesh model with 1755,392 elements. The meshes of the local areas around the tunnels were refined. The optimised mesh was selected to achieve high computing accuracy and efficiency. Finally, the CDEM solver was used to analyse this 3D model;

(9) 2D geometrical model of mining in sensitive reservoir slice: for the mining simulation, the $2 \mathrm{D}$ geometrical model of the mining direction in a sensitive reservoir slice was selected. It should be noted that the 3D model could be used for mining modelling; however, this study focused on the morphology of mining-induced fractures, crucial evolution of vertical stress, large deformation, and the separation and collapse between the roofs in the plane containing more layers. Furthermore, the 2D model could achieve higher computing efficiency for large-scale analysis compared with the 3D model; therefore, the 2D model simplification was adopted here;

(10) 2D numerical model with mesh of mining for CDEM: for the 2D geometrical model, the material parameters were assigned and meshed to obtain the 2D numerical model of mining for CDEM. ANSYS $^{\circ}$ software (http://www.ansys.com/) was used to create a mesh model, with 51,225 elements, that was refined in the specific areas near the layer contacts. The optimised mesh was used in this model. Finally, the CDEM solver was used to analyse this 2D model.

As the above CDEM models are based on numerical discretisation by elements and does not allow cracks to break through the elements, the mesh-dependent problem could be a crucial factor. Therefore, to overcome this problem, the initial refined meshes were prepared carefully to ensure that enough accurate solutions could be obtained. The optimised meshes for the models used in this study are discussed in
Section 4 to show the validity of the meshes and the stability and reliability of the computed solutions. As a further improvement, adaptive mesh refinement techniques for the FE-DE method and models have been developed recently by the authors of this paper. ${ }^{53,54}$

\subsection{Numerical models for roadway tunnelling and coal seam mining}

Conducting large-scale engineering analysis to create reasonable numerical models for roadway tunnelling and coal seam mining could be challenging, particularly in respect of high solving efficiency and effective validation by experiments. The laboratory experiments were implemented to determine the correctness of the numerical results computed by the CDEM, and both the stress evolution and the fracture morphology were well consistent with the results of previous investigations conducted by the authors of this paper. ${ }^{37,39}$ To ensure the effectiveness of the models, the basic physical parameters of the real rock were applied in the numerical models and the mechanical parameters were tested by the experiments. The CDEM models and mechanical parameters were developed in the current study to investigate large-scale models for tunnelling and mining.

Consider the 3D tunnelling model shown in Fig. 2(a). The length of each side is $50 \mathrm{~m}$, and the centres of tunnels a and $\mathrm{b}$ are $10 \mathrm{~m}$ from the boundaries in the $x$-direction and $25 \mathrm{~m}$ from the boundaries in the $y$ direction. The side length of the tunnels is $3 \mathrm{~m}$. Two sections, namely $\mathrm{A}-\mathrm{A}$ and $\mathrm{B}-\mathrm{B}$, were set to detect the deformation, stresses, and fractures. Section A-A is perpendicular to the $x$-axis and section B-B is perpendicular to the $z$-axis and through the axis of tunnel a. Twelve monitoring points were arranged in advance around the left tunnel (a) to detect the stress field and fracture field around the tunnel. The monitoring points were positioned at a distance from the tunnel, with monitoring points $1,4,7$, and 10 situated $1 \mathrm{~m}$ away; monitoring points $2,5,8$, and 11 situated $2 \mathrm{~m}$ away; and monitoring points $3,6,9$, and 12 situated $3 \mathrm{~m}$ away, as shown in the figure on the right. The working face is approximately $600 \mathrm{~m}$ from the ground surface. The horizontal and vertical in situ stresses $S_{x}, S_{y}$, and $S_{z}$ in the $x, y$, and $z$ directions are 10.5 $\mathrm{MPa}$, 16.5 MPa, and $15 \mathrm{MPa}$, respectively.

On the other hand, consider the 2D mining model shown in Fig. 2(b). The length of the sides is $400 \mathrm{~m}$ and $100 \mathrm{~m}$, respectively, and the working face is situated $100 \mathrm{~m}$ from the boundaries in the $x$-direction. Six monitoring lines are situated around the target coal seam, with the three lines above being $2 \mathrm{~m}, 6.5 \mathrm{~m}$, and $18 \mathrm{~m}$ away from the goaf roof in the middle of the immediate roof, main roof, and the strata above, respectively. The three lines below are situated $2 \mathrm{~m}, 6 \mathrm{~m}$, and $14 \mathrm{~m}$ from the goaf floor in the middle of the immediate floor, main floor, and the strata below, respectively. The working face of the target coal seam is performed from the left side to the right side. The horizontal and vertical in situ stresses $S_{x}$ and $S_{y}$ in the $x$ and $y$ directions are 10.5 MPa and 16.5 MPa, respectively, possessing the identical state of in situ stresses in the above 3D tunnelling model. 
(a) $5 \mathrm{~m}$
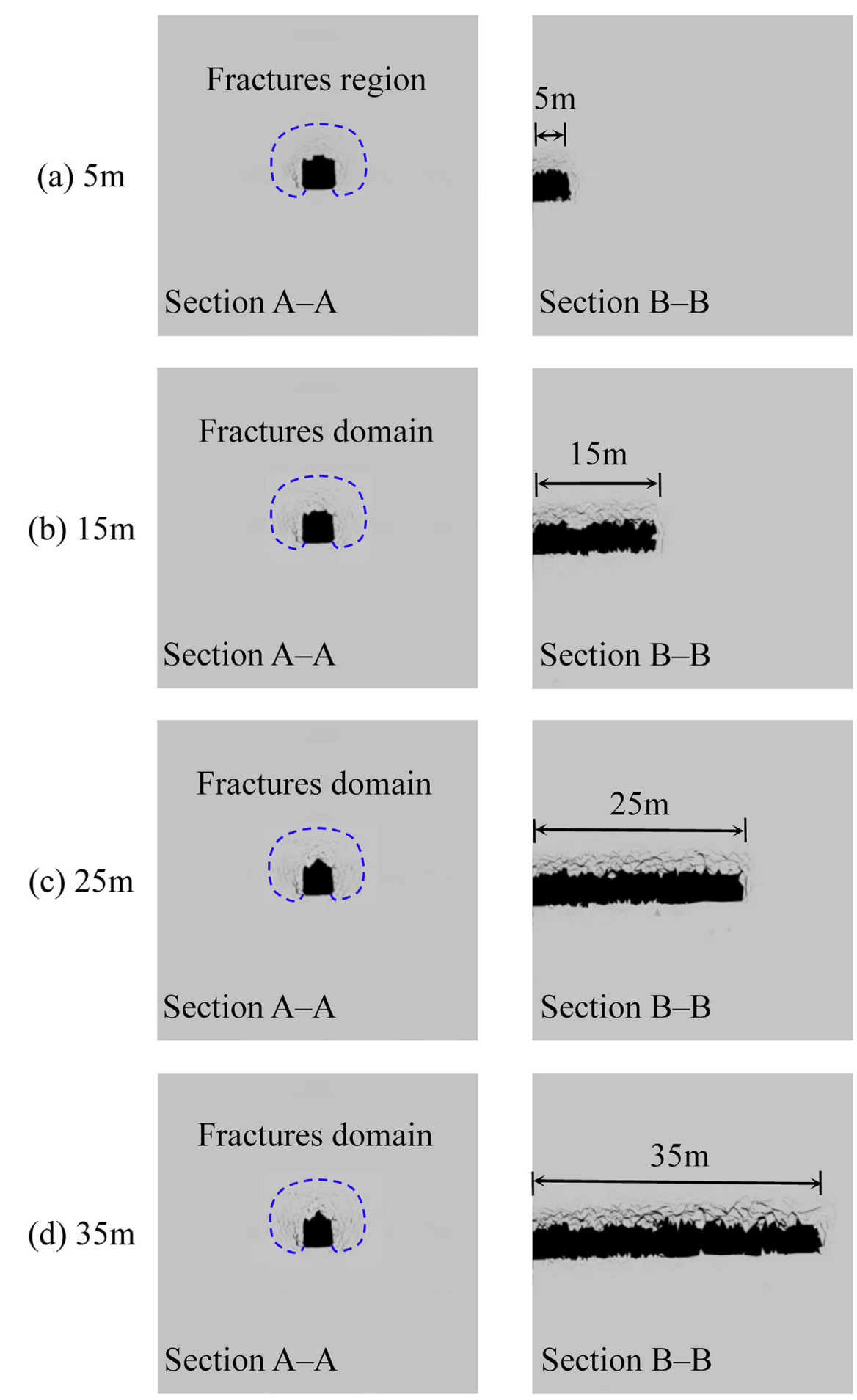

Fig. 7. Evolution of fractures in section A-A and section B-B of the tunnelling model at different tunnelling distances.

\subsection{Global procedure}

The global methodology and procedure for the CDEM computation of a mining-induced stress field and fracture field in a layered reservoir is introduced briefly here. First, the layered reconstruction CDEM models were established according to the characteristics of the natural coal seam reservoir. Subsequently, the 3D forward tunnelling model and the 2D backward mining model of the layered reservoir were analysed by using the CDEM procedure. In this procedure, the basic variables of solids, such as displacement, velocity, and stress were computed by FEM. Subsequently, based on the current stress state, the tensile and shear cracks started growing once the fracture criterion for crack generation was satisfied by the DEM. This step is defined and used to explain the computation stage of the dynamic excavation process by sequentially deleting elements. The stress field and fracture field were obtained in the current step of dynamic excavation, serving as the initial conditions for computing FE solutions in the next step. Subsequently, dynamic excavation was implemented by deleting elements sequentially for the next round. At the end of the procedure, the two tunnels were formed, and the working face was completed - the entire process of the dynamic evolution of the stress field and fracture field was obtained in this way. Furthermore, the height of the caving 
Table 5

Computed results of mining model for different initial meshes.
States
Initial mesh
Vertical stress $\sigma_{y}(\mathrm{MPa})$ at mining distance of $200 \mathrm{~m}$

Case IIa (44,934 elements)
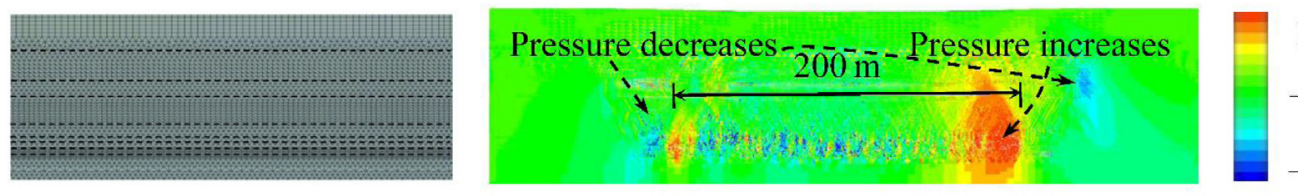

Case IIb $(51,225$ elements $)$
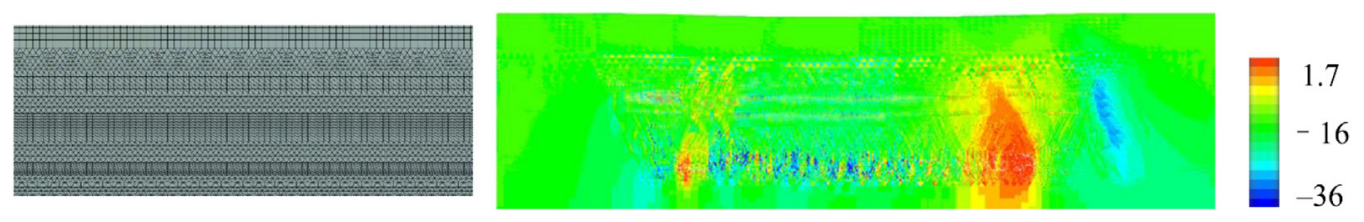

zone and the fracture zone in the surrounding rock roof could be evaluated by the numerical solutions.

\section{Results and discussion}

This study addressed the main concerns described in the introduction section, which are the layered reservoir, mining-induced large deformation, evolution of the stress field and fracture field, and the height of the caving zone and the fracture zone. For successional and complete analysis, the two representative numerical examples for coal seam mining, namely the forward roadway tunnelling model (Case I) and the backward coal seam mining model (Case II) were computed according to an approach proposed previously. In the following numerical examples, the CDEM models were used to analyse tunnelling and mining, with the image processing method introduced to simulate the layered reservoir. The material parameters were applied to the numerical models to determine the growth and distribution of the mining-induced fractures. Both cases were executed using $\mathrm{CDEM}^{38}$ on a desktop computer with an Intel ${ }^{\circ} \mathrm{Core}^{\mathrm{TM}} 3.40 \mathrm{GHz}$ CPU.

\subsection{Case I: Forward roadway tunnelling}

\subsubsection{Numerical model and conditions}

Consider the 3D tunnelling model shown in Fig. 2(a), with two tunnels to simulate simultaneously the dynamic excavation by sequentially deleting elements. There are 12 monitoring points around the left tunnel. Table 1 lists the basic mechanical parameters for seven stratum layers and the lithology. To simulate the rock joint fractures in the rock stratum layers during the mining process, a brittle fracture model was used for the joint material in the CDEM. ${ }^{41-43}$ The interfaces between the multilayers in both the tunnelling model and the mining model can separate by the conventional DEM once the tensile failure or shear failure criterion is satisfied. Tables 2 and 3 list the basic mechanical parameters of the rock strata of coal seam mining and the rock joints for ten stratum layers, as well as the lithology. To investigate the deformation and collapse of the upper stratum layers in the mining process, the refined numerical model containing multiple stratum layers was introduced. The proposed numerical models are based on numerical discretisation by elements and the cracks could not gain access into the elements. The fractures propagate along the edges of the elements by the nodes separating; therefore, the results are dependent on the state of distribution of the initial meshes. To search for and design a reasonable mesh, various meshes were investigated to determine the optimised mesh that could achieve simultaneous high computing accuracy and efficiency. In this study, the optimised mesh in the vicinity of the tunnels and the layer contacts was refined and became increasingly denser. To show the effectiveness of the models, the results of the tunnelling model with the initial optimised mesh $(1,755,392$ elements; Case Ia) are as shown in Table 4. However, to investigate mesh sensitivity, the selected denser mesh $(1,834,215$ elements; Case Ib) was used to compute the solutions. As regards the solutions of the two cases, the tunnelling-induced stress and crack network morphology are almost the same. The typical solutions for vertical stress $\sigma_{y}(\mathrm{MPa})$ in section A-A and section B-B at a tunnelling distance of $35 \mathrm{~m}$ are shown in Table 4 . The conclusion could be drawn that the optimised mesh for the model was reasonable, and the computed solutions were stable and reliable. Therefore, the computed results of the tunnelling model and mining model for different initial meshes are validated, i.e. refining the mesh would lead to the convergence of the numerical solutions. Using this numerical model and these conditions, the solutions were computed based on the CDEM as bellows of the tunnelling-induced stress, displacement, and fracture.

\subsubsection{Tunnelling-induced stress}

The evolution of vertical stress $\sigma_{y}$ in section A-A and section B-B at different tunnelling distances, namely $5 \mathrm{~m}, 15 \mathrm{~m}, 25 \mathrm{~m}$, and $35 \mathrm{~m}$ is shown in Fig. 3, indicating the stress concentration and redistribution around the tunnels. As there are high vertical stresses at the roof and bilateral walls of the tunnel, corresponding supporting or anchoring measures should be adopted in actual engineering. The evolution of vertical stress of the monitoring points of the tunnelling model at different tunnelling distances is shown in Fig. 4. The initial vertical stresses are almost the same as the in situ stress $S_{y}$, which will redistribute and reduce as the tunnelling passes. As shown in Fig. 4(a), the vertical stress of monitoring points 1-3 in the tunnel roof was reduced to zero immediately after the tunnelling had passed. As shown in Fig. 4(b)-(d), the vertical stresses of monitoring points 4, 7, and 10 on the walls of the tunnel were reduced to zero; however, as the monitoring points are located at a considerable distance from the tunnel, the stresses maintained certain values because of the influence of the in situ stress. Comparing Fig. 4(c) and (d) shows that the vertical stresses of monitoring points 10-12 are larger than the values of monitoring points 7-9. This could be ascribed to the stress superposition and interaction caused by the simultaneous dynamic excavation of the right tunnel (b). 
(a) $10 \mathrm{~m}$

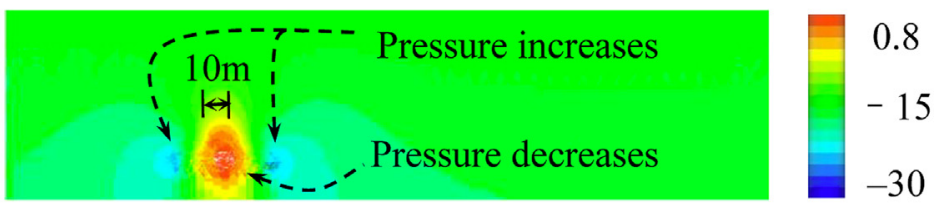

0.8

(b) $20 \mathrm{~m}$

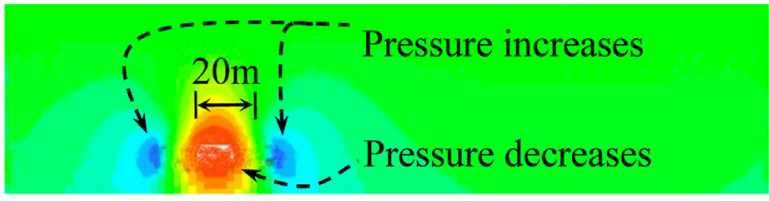

0.8

$-15$

$-30$

(c) $30 \mathrm{~m}$
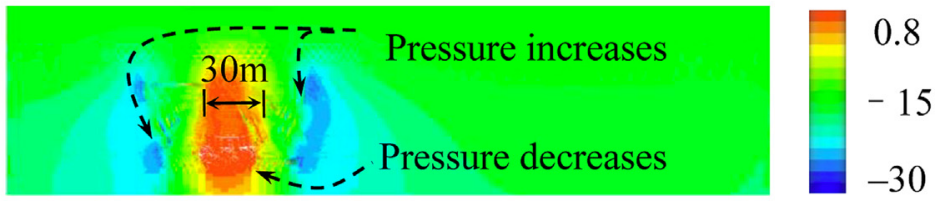

(d) $40 \mathrm{~m}$
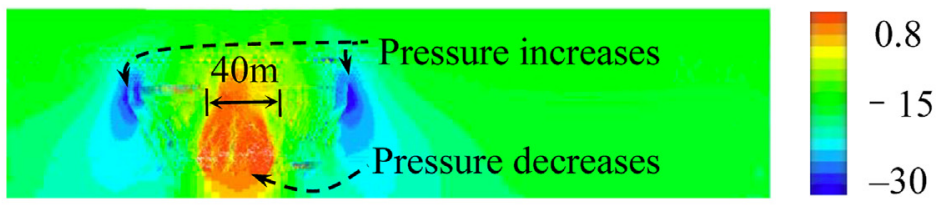

(e) $50 \mathrm{~m}$
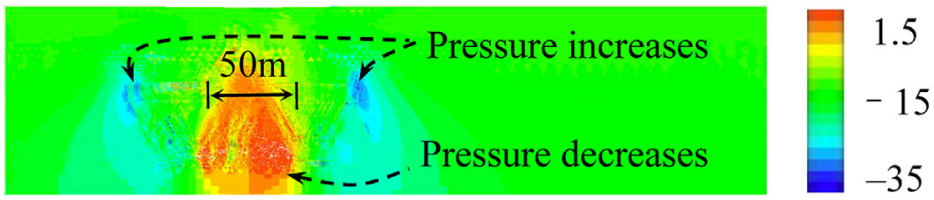

(f) $100 \mathrm{~m}$
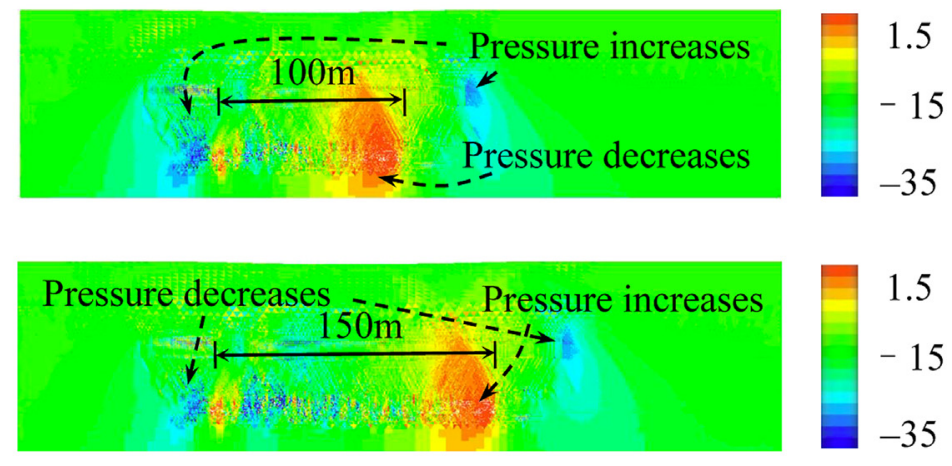

(g) $150 \mathrm{~m}$
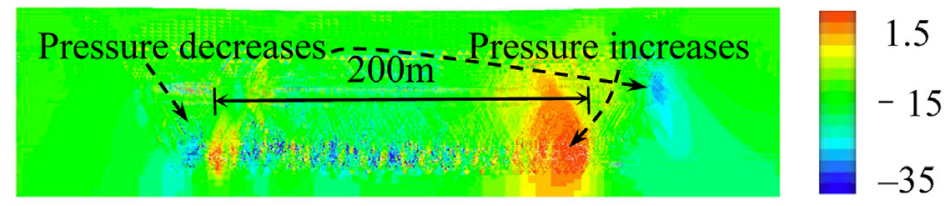

Fig. 8. Evolution of vertical stress $\sigma_{y}(\mathrm{MPa})$ of the mining model at different mining distances.

It is worth mentioning that after dynamic excavation, the stresses surrounding the rock around the roadway will redistribute, and the initial pressure stress (negative value) will even become tensile (positive value). Therefore, zero values could appear near the roadway, as shown in the results of monitoring points $1-3,4,7$, and 10 . The generation of the fractures will aggravate the above phenomenon for stress release and redistribution.

\subsubsection{Tunnelling-induced deformation and fracture}

Attention must be given to behaviours, such as the deformation and collapse of the tunnel roof and the fractures near the bilateral tunnel walls and in front of the excavation face, which are the results of the continuous evolution of tunnelling-induced stresses during excavation. The evolution of vertical displacement $u_{y}$ in section A-A and section B-B of the tunnelling model at different tunnelling distances, namely $5 \mathrm{~m}$, $15 \mathrm{~m}, 25 \mathrm{~m}$, and $35 \mathrm{~m}$, is shown in Fig. 5. This figure shows the compression deformation at the top and bottom of the tunnels at different 

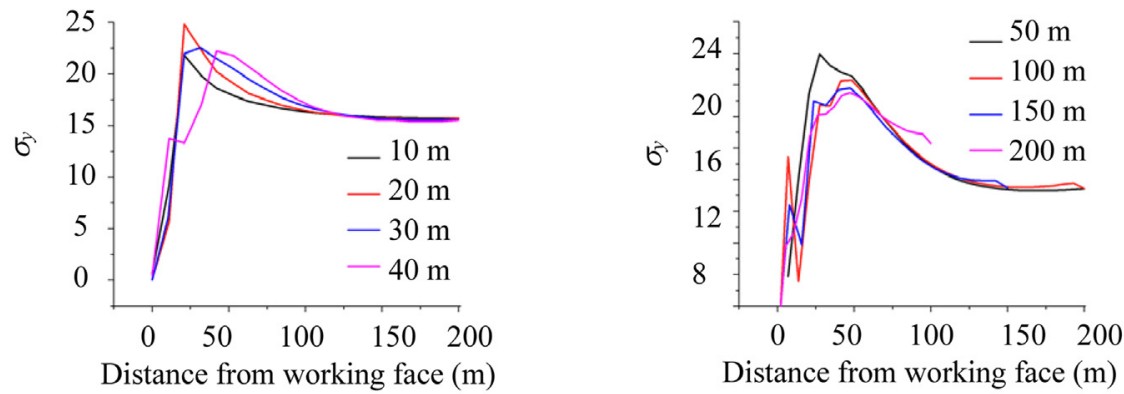

(a) Working face at $10 \mathrm{~m}, 20 \mathrm{~m}, 30 \mathrm{~m}$, and $40 \mathrm{~m}$ (b) Working face at $50 \mathrm{~m}, 100 \mathrm{~m}, 150 \mathrm{~m}$, and $200 \mathrm{~m}$

Fig. 9. Evolution of vertical stress $\sigma_{y}(\mathrm{MPa})$ of the monitoring lines of the mining model at different mining distances from the working face.

tunnelling distances. After the tunnel excavation, the tunnel roof moves downward, and the displacement field takes on an elliptical shape. With the increase in the excavation distance, the influence range increases and upward deformation of the tunnel floor occurs; however, the change in the influence range is not obvious compared with that of the tunnel roof because of the effect of the gravity of the upper rock strata.

To analyse the distribution of tunnelling-induced fractures, and because the distribution of fractures around the two tunnels is similar, the locally enlarged results of one tunnel (tunnel a) are shown. The evolution of the vertical displacement of the monitoring points of the tunnelling model at different tunnelling distances is shown in Fig. 6. As shown in Fig. 6(a) for monitoring points $1-3$ in the tunnel roof, the closer to the tunnel roof wall the monitoring points are the larger the deformation becomes. Furthermore, in the domain near monitoring point 1 , fractures appear that are caused by the large deformation. As shown in Fig. 6(b), for monitoring points 4-6 in the tunnel roof, the closer to the tunnel floor wall the monitoring points are the larger the deformation becomes, similar to the phenomenon in the tunnel roof. However, the deformation of the monitoring points in the tunnel floor is obviously smaller than is that in the tunnel roof.

Fig. 7 illustrates the evolution of the fractures in section A-A and section B-B at the different tunnelling distances. As shown in the left column in Fig. 7(a), for transverse section A-A, as the tunnel is excavated, the tunnel roof and bilateral walls show obvious delamination fractures in a fan-shaped distribution. The immediate roof consists of mudstone, of which the strength and Young's modulus, shown in Table 1, are lower relatively. A radiative fracture zone forms here that is distributed at a range of $3 \mathrm{~m}$. The bilateral walls form similar left-right symmetry fractures that gradually vanish in the far field. The immediate floor consists of siltstone, of which the strength and Young's modulus are higher relatively, forming fewer fractures around the tunnel. As shown in the right column in Fig. 7(b) for radial section B-B, the fracture field of the surrounding rock of the tunnel can be divided into two zones, namely a developed fracture zone and a micro-fracture zone. As the tunnel is excavated, the cracks in the surrounding rock appear to slip, break through, and expand to produce several new micro-fractures. Subsequently, the developed fracture zone expands and, in front of the excavation face, the rock starts to fracture and even fall off.

\subsection{Case II: Backward coal seam mining}

\subsubsection{Numerical model and conditions}

Consider the 2D mining model shown in Fig. 2(b). It has a single working face to simulate the dynamic excavation by sequentially deleting elements, and there are six monitoring lines around the target coal seam. Similar to the above tunnelling simulation, the brittle fracture model was used for the joint material in $\mathrm{CDEM}^{41-43}$ to simulate the rock joint fractures in the rock stratum during the mining process. Tables 2, 3 list the basic mechanical parameters of the rock strata of coal seam mining, as well as the rock joints. To illustrate the effectiveness of the models, the tunnelling model with the initial optimised mesh (44,934 elements; Case IIa) is as shown in Table 5, whereas, to investigate mesh sensitivity, another selected denser mesh $(51,225$ elements; Case IIb) was used to compute the solutions. As regards the solutions of the two cases, the mining-induced stress and crack network morphology are almost the same, and the typical solutions for vertical stress $\sigma_{y}(\mathrm{MPa})$ and the pressure change region at a mining distance of $200 \mathrm{~m}$ are shown in Table 5. The conclusion can be drawn that the optimised mesh for the model is reasonable, and the computed solutions are stable and reliable. We computed the solutions as bellows of the mining-induced stress, displacement, fracture, caving zone, and fracture zone based on the CDEM by using the above numerical model and conditions.

\subsubsection{Mining-induced stress}

Fig. 8 shows the evolution of the vertical stress $\sigma_{y}$ of the mining model at different mining distances. As shown in Fig. 8(a), for a mining distance of $10 \mathrm{~m}$, with the initial excavation of the coal seam, the goaf forms and, because of unloading, the initial in situ stress in this domain is redistributed. Furthermore, pressure decreases, and even tensile stress occurs in the centres of the roof and floor, and the pressure on the bilateral sides of the goaf increases. This phenomenon takes place also during the next stages of mining. As shown in Fig. 8(b) for a mining distance of $20 \mathrm{~m}$, with the collapse of the immediate roof, the fracture zone increases, and the influence range of the pressure decrease zone expands. As shown in Fig. 8(c)-(d) for mining distances of $30 \mathrm{~m}$ and $40 \mathrm{~m}$, respectively, various typical phenomena appear. These include the stress redistribution domain near the mining working face tending to become regular gradually, and the pressure decrease zone continuing to expand to form a similar triangular shape, the middle part of the main roof collapsing, and the overlying strata moving down. As shown in Fig. 8(e)-(h) for mining distances of 50-200 m, the fractured rock mass in the goaf behind the working face is recompacted and the stress and fracture distribution near the mining working face tends to become stable gradually. Consequently, the initial mining stage and stable mining stage can be defined and used to distinguish the different stages of the entire mining process. Based on the analysis with the proposed method and numerical model, the initial mining stages imply that the working face has advanced less than $50 \mathrm{~m}$, and the stresses redistribute intensely after being disturbed by the abrupt excavation. The stable mining stages imply that the working face has advanced more than $50 \mathrm{~m}$ and the mining-induced stresses in the surrounding rock strata change analogously.

Fig. 9 shows the evolution of vertical stress of the mining model at different mining distances from the working face. Fig. 9(a) and (b) show the results for the initial mining stage (working face at $10 \mathrm{~m}, 20 \mathrm{~m}$, $30 \mathrm{~m}$, and $40 \mathrm{~m}$ ) and the stable mining stage (working face at $50 \mathrm{~m}$, $100 \mathrm{~m}, 150 \mathrm{~m}$, and $200 \mathrm{~m}$ ), respectively. In the initial mining stage, the distances of the peak values of vertical stress from the working face 
(a) $10 \mathrm{~m}$

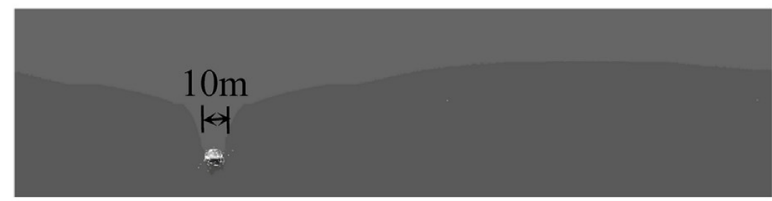

(b) $20 \mathrm{~m}$

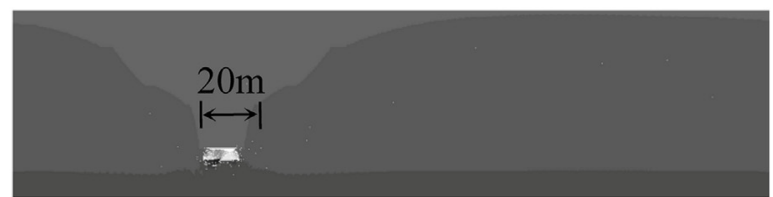

(c) $30 \mathrm{~m}$

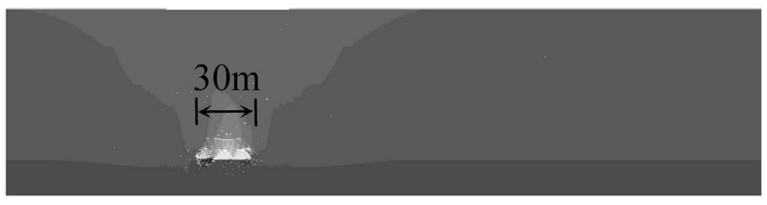

(d) $40 \mathrm{~m}$
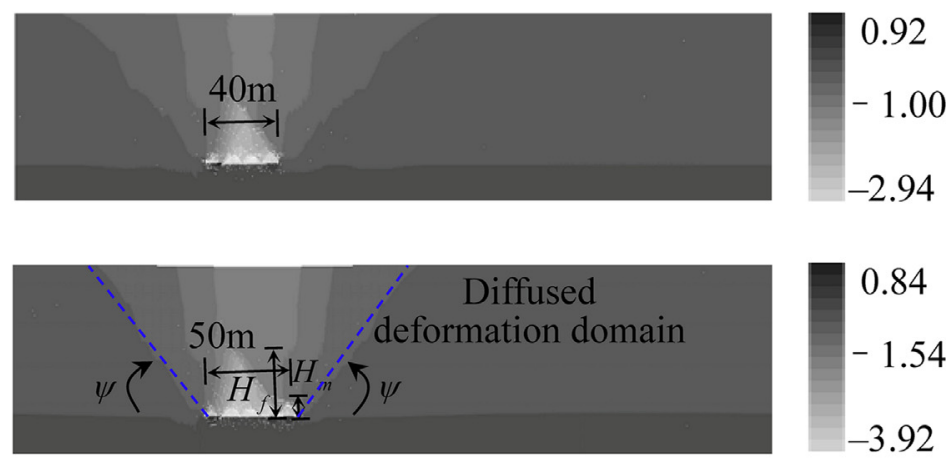

(e) $50 \mathrm{~m}$

0.84
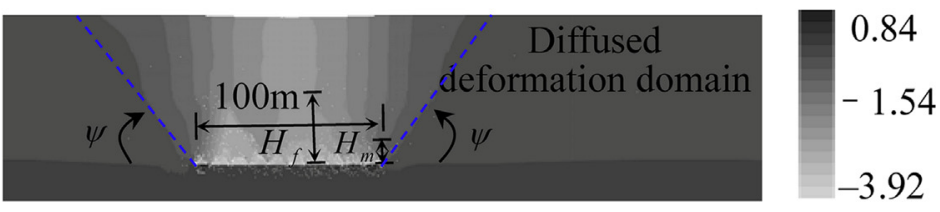

(f) $100 \mathrm{~m}$
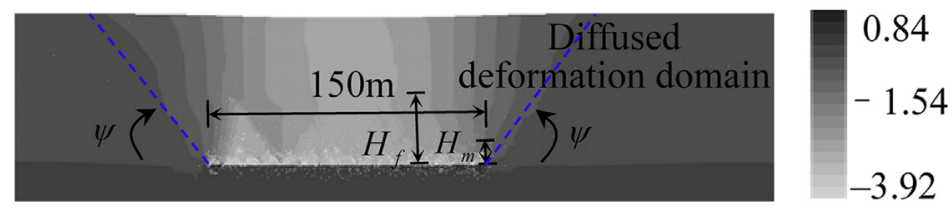

(g) $150 \mathrm{~m}$
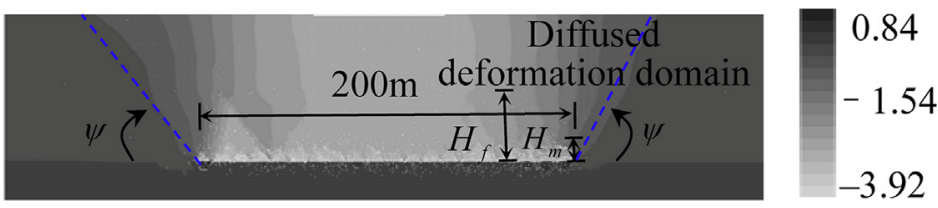

Fig. 10. Evolution of vertical displacement $u_{y}(\mathrm{~m})$ of the mining model at different mining distances.

increase as mining advances. In the stable mining stage, the peak value of vertical stress is almost $21 \mathrm{MPa}$ at a distance of $47 \mathrm{~m}$ from the working face. This has important implications for estimating reservoir collapse and fracture. However, in the initial mining stage, the peak value of vertical stress is higher than are the values in the stable case. This aspect should be given more attention and protective measures should be put in place in actual mining engineering.

\subsubsection{Mining-induced deformation and fracture}

Attention must be given to various dynamic evolution behaviours of mining-induced deformations and fractures, such as the typical phenomena of collapse in the immediate roof, bulges in the immediate floor, and compaction by the collapsed blocks. In addition, other factors that are usually ignored in multilayered rock strata must be investigated, such as the evolution of large deformation and the separation and collapse between the immediate roof and the main roof. 
(a) $10 \mathrm{~m}$
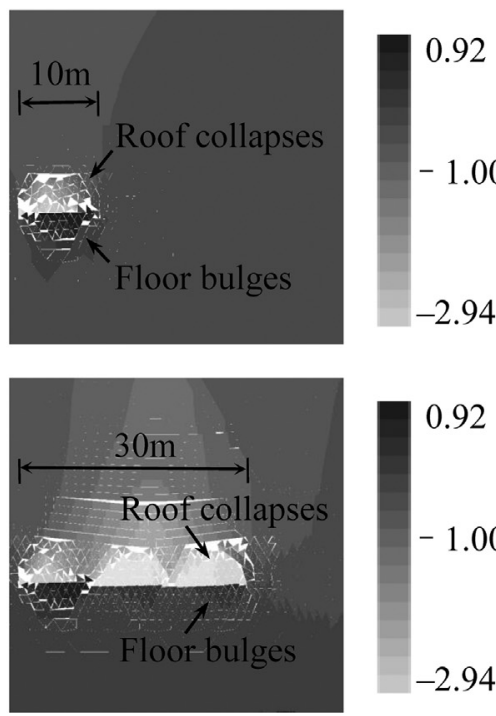

0.92

(c) $30 \mathrm{~m}$ g. 11. Evolution of fractures of the local en Figs. 10 and 11 illustrate the evolution of vertical displacement $u_{y}$
and the fractures in the local enlarged model at different mining distances, respectively. Fig. 10 (a)-(d) and Fig. 11 (a)-(d) show the initial mining stages. As shown in Figs. 10 (a) and 11 (a) for a mining distance of $10 \mathrm{~m}$, the rock stratum (height approximately $5 \mathrm{~m}$ ) on the roof collapses and the rock stratum (thickness $3 \mathrm{~m}$ ) on the floor moves upward as a bulge. As shown in Figs. 10 (b) and 11 (b) for a mining distance of $20 \mathrm{~m}$, the immediate roof of mudstone collapses under the influence of gravity and dynamic excavation, with micro-fractures appearing in the main roof of sandstone to form a similar arch shape. As shown in Figs. 10 (c) and 11 (c) for a mining distance of $30 \mathrm{~m}$, the immediate roof of mudstone collapses continually, and the fractured blocks compact in the goaf. The main roof starts to bend, producing many horizontal separation fractures, and obvious delamination occurs, with the upper strata forming a similar simple-supported beam. Discontinuous separation fractures form in the upper rock strata in the main roof. As shown in Figs. 10 (d) and 11 (d) for a mining distance of $40 \mathrm{~m}$, the immediate roof falls, and the main roof collapses, producing massive fractured rock blocks that fill the goaf. Fig. 10 (e)-(h) show the stable mining stages for mining distances of $50 \mathrm{~m}, 100 \mathrm{~m}, 150 \mathrm{~m}$, and $200 \mathrm{~m}$, respectively. The overlying mudstone and sandstone strata collapse, as the development of the fracture zone leads to delamination and, in particular, the goaf roof shows typical diffused deformation. In the stable mining stages, the diffused deformation domain and the displacement angle $\psi$ of stratum diffusion (dashed blue lines) remain stable, and $\psi$ in the stable mining stages is evaluated quantitatively at approximately $55^{\circ}$. This is shown by the evolution of vertical displacement of the mining model at different mining distances in Fig. 10 (e)-(h). As the working face advances, three stages of separation, bending, and compaction of the overlying rock occur. The caving zone and fracture zone are stable at a height of $H_{m}=10 \mathrm{~m}$ and $H_{f}=31 \mathrm{~m}$, respectively, as shown in Fig. 10 (e)-(h) and will be discussed in detail in the next section.

Fig. 12 shows the evolution of vertical displacement on the goaf roof of the monitoring lines at different mining distances. As shown in Fig. 12 (a) for a mining distance of $10 \mathrm{~m}$, the immediate roof starts to collapse, reaching deformation of $0.69 \mathrm{~m}$, with the main roof and rock strata above showing relatively smaller deformation. As shown in Fig. 12 (b) for a mining distance of $20 \mathrm{~m}$, the immediate roof collapses integrally to reach deformation of $1.6 \mathrm{~m}$, with the main roof and the rock strata above showing separation. As shown in Fig. 12 (c) for a mining distance of $30 \mathrm{~m}$, the main roof starts to collapse, with the rock strata above the main roof showing bending and sinking, and obvious separation at the immediate roof, main roof, and the strata above. As shown in Fig. 12 (d) for a mining distance of $40 \mathrm{~m}$, the main roof starts to collapse completely, and the separation at the immediate roof, main roof, and strata above is compacted. In the stable mining stage, the evolution of vertical displacement on the goaf floor of the monitoring lines at different mining distances is shown in Fig. 12 (e)-(h). It is clear that the sinkage of the rock strata is almost the same and stable, and the deformation decreases slightly from the immediate roof and main roof to the strata above.

In coal seam mining, the goaf floor is prone to water inrush accidents; therefore, monitoring the deformation and fracturing of the goaf floor has practical significance. Fig. 13 provides the evolution of vertical displacement on the goaf roof of the monitoring lines at different mining distances. As shown in Fig. 13 (a) for a mining distance of $10 \mathrm{~m}$, the goaf floor shows an upward deformation phenomenon because of the initial unloading effect of the goaf, with the immediate floor showing maximum deformation of approximately $0.55 \mathrm{~m}$, the main floor showing less deformation, and the strata below showing almost no displacement. As shown in Fig. 13 (b)-(d) for mining distances of $20 \mathrm{~m}$, $30 \mathrm{~m}$, and $40 \mathrm{~m}$, the upward deformation phenomenon in the goaf floor advances along with the advancing working face, with the maximum deformation being maintained at approximately $0.2 \mathrm{~m}$, which is smaller obviously than is the initial maximum deformation of $0.55 \mathrm{~m}$. This could be ascribed to stress near the working face being released because of the mining activity; however, the unloading effect of the rock is not significant compared with that of the initial mining stage. In the stable mining stage, as shown in Fig. 13 (e)-(h) for mining distances of $50 \mathrm{~m}$, $100 \mathrm{~m}, 150 \mathrm{~m}$, and $200 \mathrm{~m}$, the fractured blocks behind the working face are constantly compacted and the upward deformation of the goaf floor decreases with the increase in mining distance. Furthermore, the immediate floor and main floor show similar collapse.

\subsubsection{The height of the caving zone and fracture zone}

Some mining-induced behaviours, i.e. diffused deformation, subsidence, collapse, and fracture are crucial to mining engineering. In this study, both the large-scale analysis of engineering problems and smaller-scale analysis of laboratory experiments have been introduced to validate the reliability of the results computed by the proposed models, in particular for the deformation domain, caving zone, fractured zone, and roof collapse zone. Because of the large-scale measurement and the complexity of geomechanical conditions in actual engineering, in large-scale analysis of actual problems, it is challenging to obtain adequate data for validation. However, an instance of 


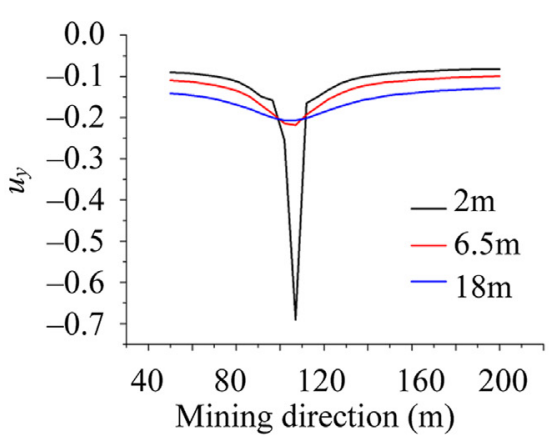

(a) Mining distance $10 \mathrm{~m}$

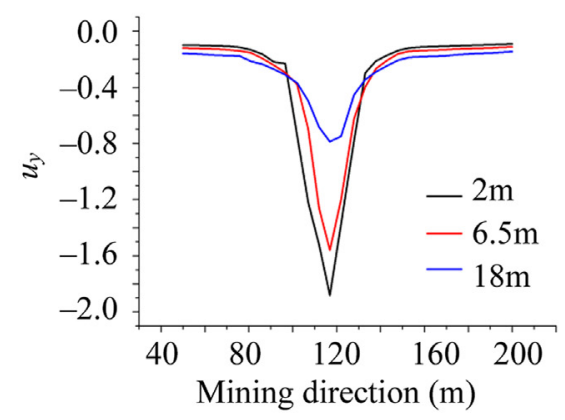

(c) Mining distance $30 \mathrm{~m}$

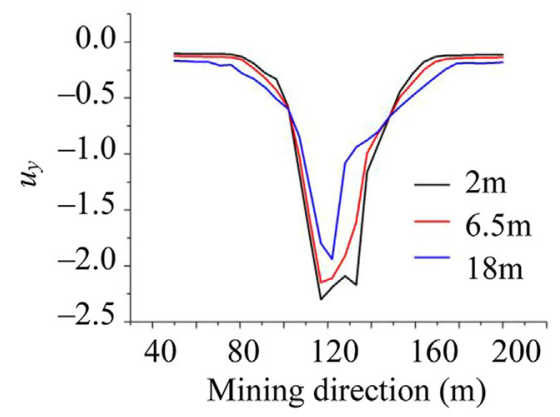

(e) Mining distance $50 \mathrm{~m}$

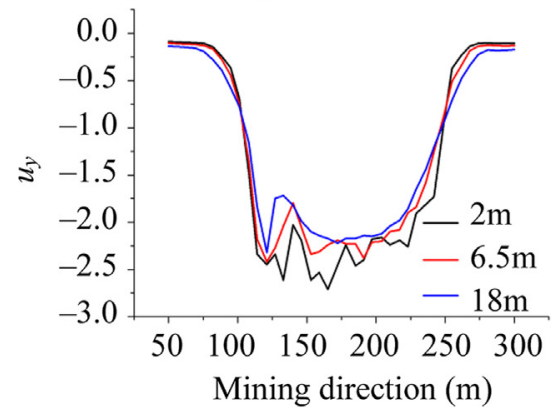

(g) Mining distance $150 \mathrm{~m}$

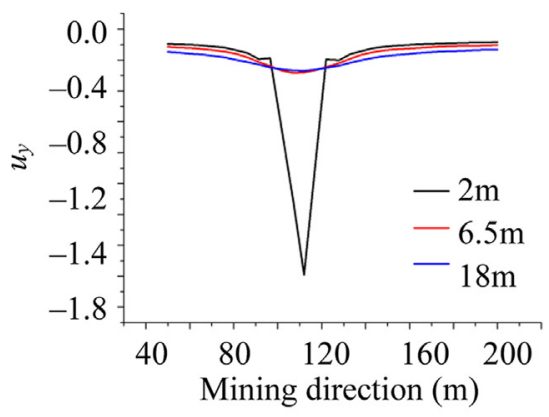

(b) Mining distance $20 \mathrm{~m}$

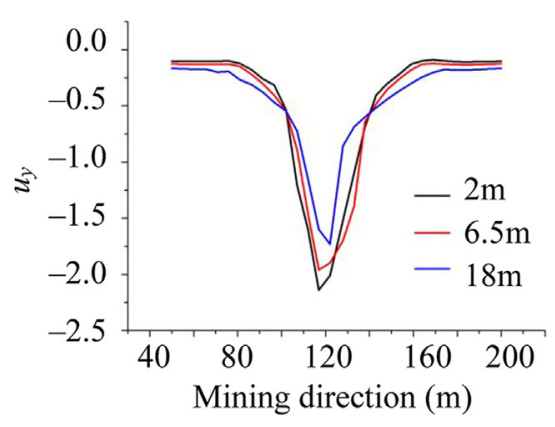

(d) Mining distance $40 \mathrm{~m}$

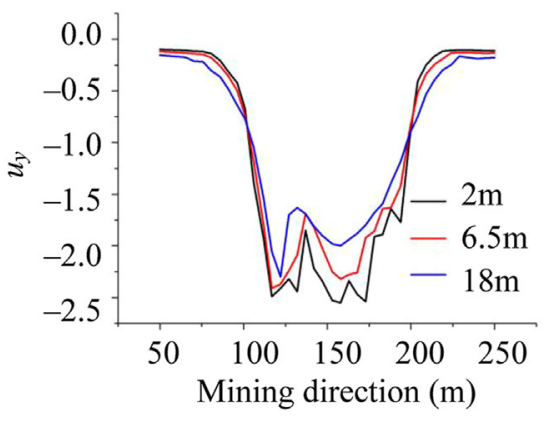

(f) Mining distance $100 \mathrm{~m}$

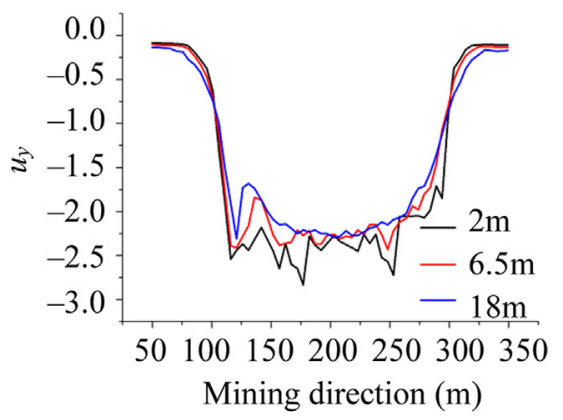

(h) Mining distance $200 \mathrm{~m}$

Fig. 12. Evolution of vertical displacement $u_{y}(\mathrm{~m})$ on the goaf roof of the mining model at different mining distances.

representative actual large-scale mining engineering is considered, ${ }^{55}$ to which diffused deformation and subsidence profiles are introduced to validate the reliability of the computed results. The typical computed results for a mining distance of $150 \mathrm{~m}$ and the diffused deformation by the proposed model are listed in Fig. 14 (a). Furthermore, the predicted and measured results of the subsidence profiles for this actual largescale mining engineering instance were selected as shown in Fig. 14 (b). It is clear that the diffused deformation and subsidence profiles are almost consistent; however, the computed displacement angle $\psi$ of $55^{\circ}$ is somewhat different from the predicted and measured values because the geometric and physical parameters of the models are not exactly the same.

As regards roof collapse, the representative computed results at different mining distances of $30 \mathrm{~m}$ and $40 \mathrm{~m}$ by the proposed mining model are listed respectively in the left figure and right figure of Fig. 15 (a). It is clear that the first and second instances of large-scale roof collapse occurred at a mining distance of $30 \mathrm{~m}$, with the separation appearing at the top of the roof because of the large deformation. Furthermore, the remaining major roof layers still propped up the mined-out area, leading to the typical arching effect that transferred the 


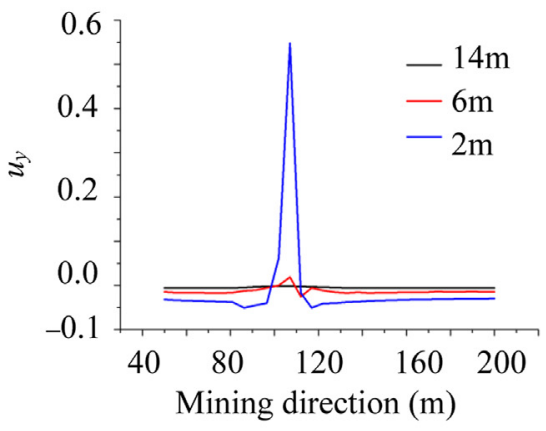

(a) Mining distance $10 \mathrm{~m}$

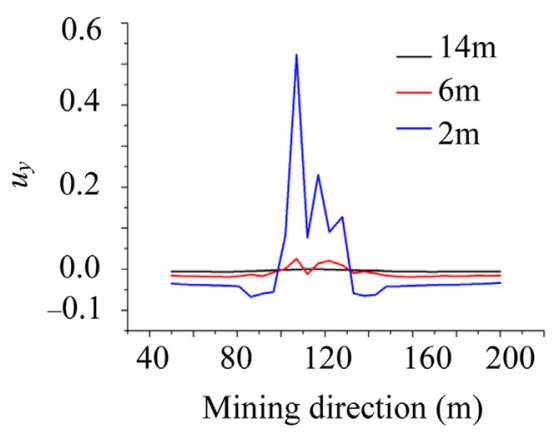

(c) Mining distance $30 \mathrm{~m}$

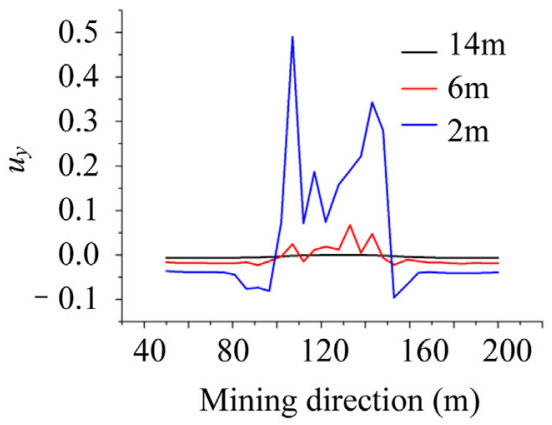

(e) Mining distance $50 \mathrm{~m}$

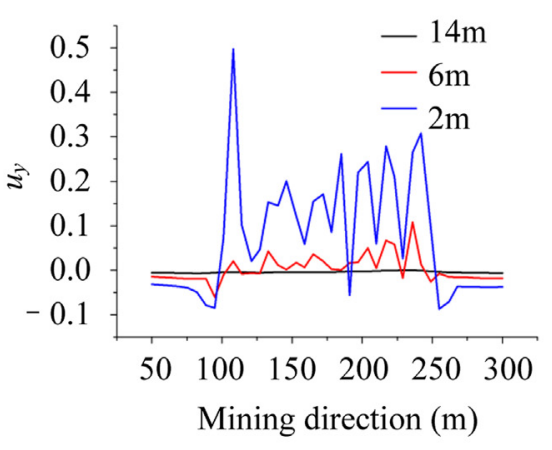

(g) Mining distance $150 \mathrm{~m}$

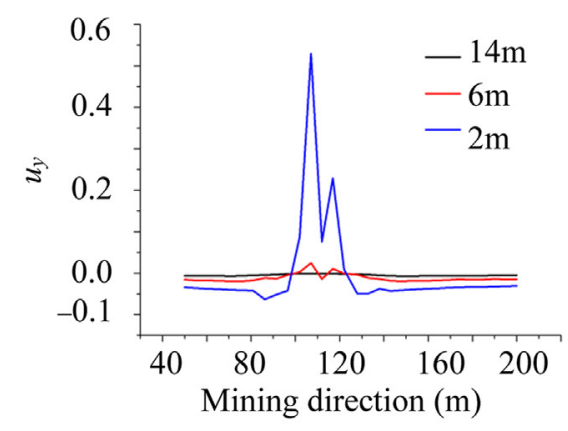

(b) Mining distance $20 \mathrm{~m}$

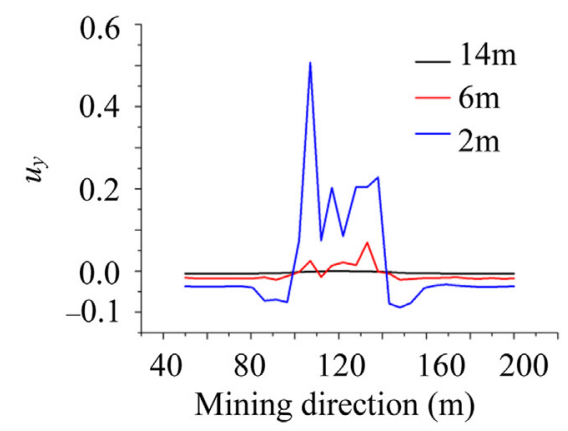

(d) Mining distance $40 \mathrm{~m}$

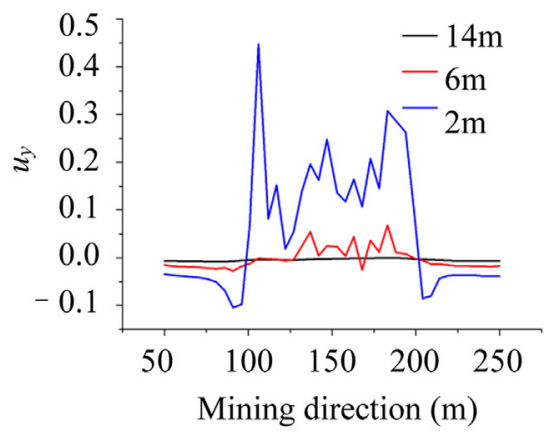

(f) Mining distance $100 \mathrm{~m}$

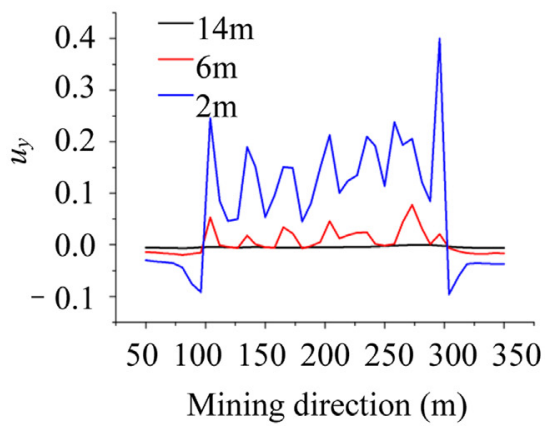

(h) Mining distance $200 \mathrm{~m}$

Fig. 13. Evolution of vertical displacement $u_{y}(\mathrm{~m})$ on the goaf floor of the mining model at different mining distances.

overburden load to the two sides of the mined-out area. Further, advancing to a mining distance of $40 \mathrm{~m}$, the third large-scale roof collapse occurred following the second roof collapse, and, subsequently, the major roof layer collapsed. This means that the arching effect no longer existed to induce reduction of the support load. A representative 2D physical multilayered mining model for experimental research was considered, ${ }^{56}$ of which the geometric sizes were $5 \mathrm{~m}$ and $2 \mathrm{~m}$, and the similarity theory was used to simulate the geometrical and material parameters. As shown in Fig. 15 (b), for the 59th excavation stage of the physical model, the main roof layers, within a depth of $190-540 \mathrm{~mm}$ above the mined-out area and involving $150 \mathrm{~mm}$ thick fine sandstone, $30 \mathrm{~mm}$ thick sandy mudstone, and $170 \mathrm{~mm}$ thick siltstone, collapsed suddenly as the first and second large-scale roof collapse events occurred. Subsequently, the third large-scale roof collapse occurred after the second roof collapse, involving $1180 \mathrm{~mm}$ thick layers consisting of mudstone, fine sandstone, and sandy mudstone. The deformation and stress monitored in the realistic roof collapse process, as well as the various typical phenomena, i.e. the separation of rock strata, the 
(a) Computed results
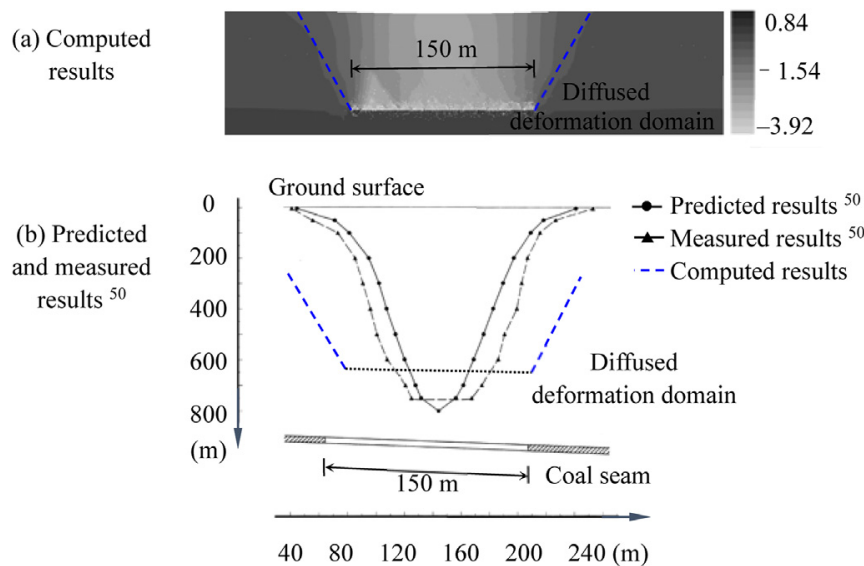

Fig. 14. Diffused deformation comparison of the computed results by the proposed model and the predicted, measured results in actual large-scale engineering.

arching effect, and subsequent support load reduction that were monitored in laboratory experiments are shown to be consistent with the computed results.

The overlying rock strata on the goaf introduce many fractures along with the disturbance of mining. According to the degree of damage, such fracturing can be divided into the caving zone, fracture zone, and the bending subsidence zone in the surrounding rock roof. These are commonly called the 'top three zones'. The coal mining damage and surface subsidence are affected mainly by the height of these three zones; therefore, determining the range of the three zones is important in detecting the movement of the overlying rock and optimising mining techniques.

Based on the experimental tests and the actual engineering, the height of the caving zone and the fractured zone can be computed by the experiential relationship with the height of the working face. ${ }^{57-61}$ For the mudstone overlying the coal seam, the maximum height of the caving zone was computed as:

$H_{m}=\alpha h$,

where $H_{m}$ is the maximum height of the caving zone, $h$ is the height of the working face, and $\alpha$ is the coefficient with the value $3-4$. The height of the fractured zone for water flow was computed as:

$H_{f}=\frac{100 h}{1.6 h+3.8} \pm 5.6$,

where $H_{f}$ is the height of the fractured zone for water flow.

With the height of working face $h$ at $3 \mathrm{~m}$, using Eqs. (12) and (13), the experiential solution $H_{m}$ was 9-12 m and the experiential solution $H_{f}$ was $29.8-40.4 \mathrm{~m}$. On the other hand, in numerical simulation results, $H_{m}$ and $H_{f}$ are detected by computed solutions of the caving zone and fractured zone by the proposed method and the numerical model, in which the zones were recorded as elements separating at the node if the fracture criteria were satisfied. $H_{m}$ and $H_{f}$ have been marked in stable mining stages, i.e. the working face advancing $50 \mathrm{~m}, 100 \mathrm{~m}, 150 \mathrm{~m}$, and $200 \mathrm{~m}$, as shown in Fig. 10 (e)-(h). Based on the above computation strategy, $H_{m}$ and $H_{f}$ were detected as $10 \mathrm{~m}$ and $31 \mathrm{~m}$, respectively, which is consistent with the experiential solutions. This result shows that the proposed numerical model and method could evaluate the evolution of the mining-induced caving zone and fracture zone adequately.

For validating the effectivity and reliability of the numerical model and results, the results in actual large-scale engineering and local smallscale specimen have been used to compare and validate the diffused deformation and roof collapse obtained by the computed results, measured results, and experimental results. The height of the caving zone and the fracture zone in the surrounding rock roof was evaluated by the numerical solutions, which were compared and analysed by experiential equations and solutions. In addition, the displacement angle of the stratum during the stable mining stages was evaluated quantitatively, in which the evolutionary process diffused deformation and subsidence profiles were detected numerically and verified by some predicted and measured results. The validity of the computed results indicates that the proposed numerical model and procedure can be extended to investigate the dynamic evolution of mining-induced stresses and fractures of multilayered rock strata in other, more-complex working conditions.

\section{Conclusions}

In this study, we established CDEM models for multilayered rock strata and investigated the mining-induced stress field and fractures in forward roadway tunnelling and backward coal seam mining. Our main conclusions are as follows:

The CDEM was applied to analyse stress evolution, and fracture initiation and propagation. To overcome the difficulties of fracture simulation in conventional FEM and to simulate the discontinuous fractures and separation that occur in the interfaces between the rock strata, factors such as deformation, slippage, and cleavage inside the solid elements and between the element interfaces were allowed in the CDEM.

The multi-material CDEM model, consisting of coal seams and multilayered surrounding rock strata, was constructed by image processing and reconstruction approaches using the geometrical and physical parameters that were extracted from the natural coal mine sites. (a) Computed results

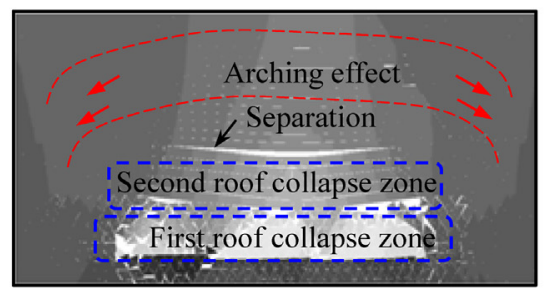

(b) Experimental results 51
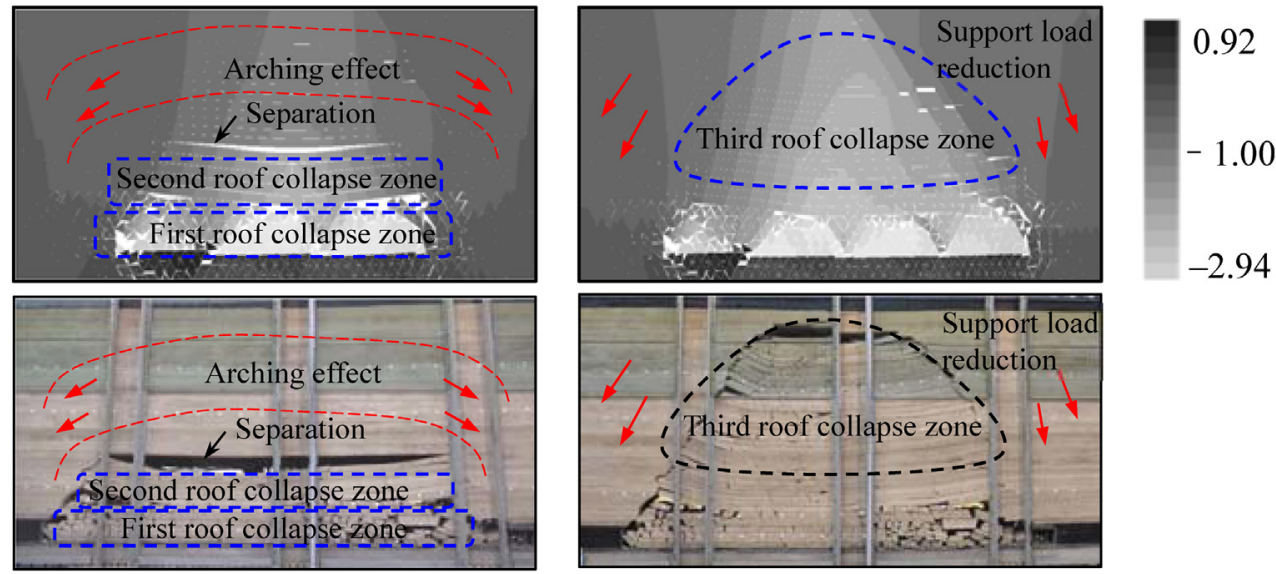

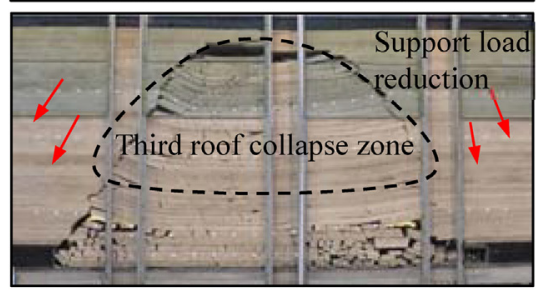

Fig. 15. Roof collapse comparison of computed results by proposed model and experimental results by local small-scale specimen. 
The optimised mesh was investigated to achieve simultaneous high computing accuracy and efficiency, and guarantee the stable and reliable computed solutions. The computed solutions of the reconstructed CDEM model showed that the mining-induced stress and fractures were consistent with the field monitoring phenomena and experiential observations.

The dynamic evolution processes of the stress field and fracture field in forward roadway tunnelling were probed. The significant stress concentration and compression deformation at the top of the rock roof and the bottom of the rock floor were computed effectively to evaluate the initiation and propagation process of the tunnelling induced fractures. Along with the continuous advancing of the excavation, the caving zone of the tunnel roof increased and, near the bilateral tunnel walls, the fractures decreased gradually toward the far field. However, in front of the excavation face, the rock started to fracture and even fall off.

The dynamic evolution processes of the stress field and fracture field in backward coal mining were simulated. The typical phenomena of roof collapse in the immediate roof, floor bulges in the immediate floor, and compaction of the collapsed blocks were acquired successfully. The evolution of large deformation and the separation and collapse between the immediate roof and the main roof were simulated effectively, showing the destruction feature in the multilayered rock strata, which, conventionally, had been ignored.

The height of the caving zone and fracture zone in the surrounding rock roof was evaluated. In accordance with the height of the working face, the computed solutions by the proposed method for the natural coal mine sites indicated maximum heights of $10 \mathrm{~m}$ and $31 \mathrm{~m}$ for the mining-induced caving zone and fracture zone, respectively. This is consistent with the field monitoring phenomena and experiential observations. Both the large-scale analysis of engineering problems and smaller-scale analysis of laboratory experiments have been introduced to validate the reliability of the results computed by the proposed models, in particular for the deformation domain, caving zone, fractured zone, and roof collapse zone. This result shows that the proposed numerical model and method could evaluate the evolution of the caving zone and fracture zone satisfactorily.

This study presents a promising approach to analyse numerically and understand the dynamic evolution behaviours of mining-induced stresses, fractures, separation, and collapse within multilayered rock strata during tunnelling and mining. The proposed CDEM facilitates simulation of the discontinuous fractures, separations, collapse, and caving within multilayered rock strata that are generally difficult to handle with conventional numerical methods. An extension to the coupling of multi-fields and the heterogeneous properties of the rock strata would be a straightforward step. Future work will consider the fluid flow and heat transfer effects in the deep rock strata, as well as the heterogeneous rock masses involved in the development of CDEM models.

\section{Funding}

This work was supported by the State Key Research Development Program of China, the Ministry of Science and Technology of China [Grant No. 2016YFC0600705], the National Natural Science Foundation of China [Grant Nos. 51727807, 51674251, 51374213, 51125017, 41877275, and 51608301], National Major Project for Science and Technology of China, the Ministry of Science and Technology of China [Grant No. 2017ZX05003-006], and the China Postdoctoral Science Foundation [Grant Nos. 2018T110158, 2016M601170, and 2015M571030].

\section{Declaration of interest}

None.

\section{References}

1. Diederichs MS, Kaiser PK, Eberhardt E. Damage initiation and propagation in hard rock during tunnelling and the influence of near-face stress rotation. Int $J$ Rock Mech Min Sci. 2004;41(5):785-812.

2. Guo H, Yuan L, Shen B, Qu Q, Xue J. Mining-induced strata stress changes, fractures and gas flow dynamics in multi-seam longwall mining. Int $J$ Rock Mech Min Sci. 2012;54:129-139.

3. Shen B, King A, Guo H. Displacement, stress and seismicity in roadway roofs during mining-induced failure. Int J Rock Mech Min Sci. 2008;45(5):672-688.

4. Palei SK, Das SK. Sensitivity analysis of support safety factor for predicting the effects of contributing parameters on roof falls in underground coal mines. Int J Coal Geol. 2008;75(4):241-247.

5. Guo H, Shen B, King A, Cousens D. Roof fall project report. CSIRO exploration and mining report $1182 \mathrm{C} ; 2003$.

6. Li T, Cai MF, Cai M. A review of mining-induced seismicity in China. Int $J$ Rock Mech Min Sci. 2007;44(8):1149-1171.

7. Lu Y, Wang L. Numerical simulation of mining-induced fracture evolution and water flow in coal seam floor above a confined aquifer. Comput Geotech. 2015;67:157-171.

8. Kaiser PK, Yazici S, Maloney S. Mining-induced stress change and consequences of stress path on excavation stability - a case study. Int J Rock Mech Min Sci. 2001;38(2):167-180.

9. Chen J, Mishra M, Zahl E, Dunford J, Thompson R. Longwall mining-induced abutment loads and their impacts on pillar and entry stability. In: Proceedings of the 21st International Conference on Ground Control in Mining, Morgantown; 11-17; 2002.

10. Seedsman R. The stress and failure paths followed by coal mine roofs during longwall extraction and implications to tailgate support. In: Proceedings of the 20th International Conference on Ground Control in Mining, Morgantown; 42-49; 2001.

11. Shepherd J, Lewandowski T. Instrumentation of roof support for colliery pillar extraction. In: Szwedzicki T, ed. Geotechnical instrumentation and monitoring in open pit and underground mining; 409-516; 1993.

12. Zahl E, Dunford J, Larson M, Brady T, Chen J. Stress measurements for safety decisions in longwall coal mines. In: Proceedings of the 21st International Conference on Ground Control in Mining, Morgantown; 45-52; 2002.

13. Wu L, Cui C, Geng N, Wang J. Remote sensing rock mechanics (RSRM) and associated experimental studies. Int J Rock Mech Min Sci. 2000;37(6):879-888.

14. Cai M, Kaiser PK, Martin CD. Quantification of rock mass damage in underground excavations from microseismic event monitoring. Int J Rock Mech Min Sci. 2001;38(8):1135-1145.

15. Lucier AM, Zoback MD, Heesakkers V, Reches Z, Murphy S. Constraining the far-field in situ stress state near a deep South African gold mine. Int $J$ Rock Mech Min Sci. 2009;46(3):555-567.

16. Kang H, Zhang X, Si L, Wu Y, Gao F. In-situ stress measurements and stress distribution characteristics in underground coal mines in China. Eng Geol. 2010;116(3):333-345

17. Barla G. Squeezing rocks in tunnels. ISRM News J. 1995;2(3):44-49.

18. Yassaghi A, Salari-Rad H. Squeezing rock conditions at an igneous contact zone in the Taloun tunnels, Tehran-Shomal freeway. Iran: A case Study Int J Rock Mech Min Sci. 2005;42(1):95-108.

19. Dalgıç S. Tunneling in squeezing rock, the Bolu tunnel, Anatolian Motorway, Turkey. Eng Geol. 2002;67(1):73-96.

20. Debernardi D, Barla G. New viscoplastic model for design analysis of tunnels in squeezing conditions. Rock Mech Rock Eng. 2009;42(2):259-288.

21. Karampinos E, Hadjigeorgiou J, Turcotte P. Discrete element modelling of the influence of reinforcement in structurally controlled squeezing mechanisms in a hard rock mine. Rock Mech Rock Eng. 2016;49(12):4869-4892.

22. Wang C, Wang Y, Lu S. Deformational behaviour of roadways in soft rocks in underground coal mines and principles for stability control. Int $J$ Rock Mech Min Sci 2000;37(6):937-946.

23. Mark C, Gale W, Oyler D, Chen J. Case history of the response of a longwall entry subjected to concentrated horizontal stress. Int J Rock Mech Min Sci. 2007;44(2):210-221.

24. Palchik V. Localization of mining-induced horizontal fractures along rock layer interfaces in overburden: field measurements and prediction. Environ Geol. 2005;48(1):68-80.

25. Profit M, Dutko M, Yu J, Angus D, Baird A. Complementary hydro-mechanical coupled finite/discrete element and microseismic modelling to predict hydraulic fracture propagation in tight shale reservoirs. Comput Part Mech. 2016;3(2):229-248.

26. Wang Y, Yang Ju, Zhuang Z, Li C. Adaptive finite element analysis for damage detection of non-uniform Euler-Bernoulli beams with multiple cracks based on natural frequencies. Eng Comput. 2018;35(3):1203-1229.

27. Sukumar N, Belytschko T. Arbitrary branched and intersecting cracks with the extended finite element method. Int J Numer Meth Eng. 2000:48:1741-1760.

28. Potyondy DO, Cundall PA. A bonded-particle model for rock. Int J Rock Mech Min Sci. 2004;41(8):1329-1364

29. Jing L, Ma Y, Fang Z. Modeling of fluid flow and solid deformation for fractured rocks with discontinuous deformation analysis (DDA) method. Int J Rock Mech Min Sci. 2001;38(3):343-355.

30. Lanaro F, Sato T, Stephansson O. Microcrack modelling of Brazilian tensile tests with the boundary element method. Int J Rock Mech Min Sci. 2009;46(3):450-461.

31. Jiang M, Yu H, Harris D. Discrete element modelling of deep penetration in granular soils. Int J Numer Anal Meth Geomech. 2006;30(4):335-361.

32. Gao F, Stead D, Kang H. Numerical simulation of squeezing failure in a coal mine roadway due to mining-induced stresses. Rock Mech Rock Eng. 2015;48(4):1635-1645. 
33. Universal distinct element code (UDEC), version 5.0. Minneapolis, MN: Itasca Consulting Group, Inc.; 2011.

34. 3D distinct element code (3DEC), version 5.2.247. Minneapolis, MN: Itasca Consulting Group, Inc.; 2017.

35. Particle flow code in three dimensions (PFC3D), version 4.0. Minneapolis, MN: Itasca Consulting Group, Inc.; 2013.

36. Peng P, Ju Y, Wang Y, Wang S, Gao F. Numerical analysis of the effect of natural micro-cracks on the supercritical $\mathrm{CO}_{2}$ fracturing crack network of shale rock based on bonded particle models. Int J Numer Anal Meth Geomech. 2017;41(18):1992-2013.

37. Munjiza A, Owen DJR, Bicanic N. A combined finite-discrete element method in transient dynamics of fracturing solids. Eng Comput. 1995;12(2):145-174.

38. Munjiza A, Andrews KRF, White JK. Combined single and smeared crack model in combined finite-discrete element analysis. Int J Numer Meth Eng. 1999;44(1):41-57.

39. Mahabadi OK, Lisjak A, Grasselli G, Munjiza A. Y-Geo: a new combined finite-discrete element numerical code for geomechanical applications. Int J Geomech. 2012;12(6):676-688.

40. Lisjak A, Garitte B, Grasselli G, Müller HR, Vietor T. The excavation of a circular tunnel in a bedded argillaceous rock (Opalinus Clay): short-term rock mass response and FDEM numerical analysis. Tunn Undergr Space Tech. 2015;45:227-248.

41. Wang L, Li S, Zhang G, Ma Z, Zhang L. A GPU-based parallel procedure for nonlinear analysis of complex structures using a coupled FEM/DEM approach. Math Probl Eng. 2013;9:841-860. https://doi.org/10.1155/2013/618980.

42. Ju Y, Liu P, Chen J, Yang Y, Ranjith PG. CDEM-based analysis of the 3D initiation and propagation of hydrofracturing cracks in heterogeneous glutenites. J Nat Gas Sci Eng. 2016;35:614-623.

43. Ju Y, Chen J, Wang Y, Gao F, Xie H. Numerical analysis of hydrofracturing behaviours and mechanisms of heterogeneous reservoir glutenite, using the continuumbased discrete element method while considering hydro-mechanical coupling and leak-off effects. J Geo Res: Solid Earth. 2018;123(5):3621-3644.

44. Xu W, Yue Z, Hu R. Study on the mesostructure and mesomechanical characteristics of the soil-rock mixture using digital image processing based finite element method. Int J Rock Mech Min Sci. 2008;45(5):749-762

45. Liu P, Ju Y, Ranjith PG, Zheng Z, Chen J. Experimental investigation of the effects of heterogeneity and geostress difference on the 3D growth and distribution of hydrofracturing cracks in unconventional reservoir rocks. J Nat Gas Sci Eng. 2016;35:541-554.

46. Bieniawski ZT. Mechanism of brittle fracture of rock: Part I-theory of the fracture process. Int J Rock Mech Min Sci Geomech Abstr. 1967;4(4):395-406.

47. Mohr O. Welche Umstande bedingen die Elastizitatsgrenze und den Bruch eines materials. Z Des Ver Dtsch Ing. 1900;46:1572-1577.

48. Li S, Lian Z, Wang J. Effect of rock mass structure and block size on the slope stability-physical modeling and discrete element simulation. Sci China Ser E Eng Mat Sci. 2005;48:1-17.

49. Fast Lagrangian Analysis of Continua (FLAC), Version 6.0. Minneapolis, MN: Itasca Consulting Group, Inc.; 2016.

50. Tang C, Tang S. Applications of rock failure process analysis (RFPA) method. J Rock Mech Geotech Eng. 2011;3(4):352-372.

51. Wang Y, Zhao M, Li S, Wang J. Stochastic structural model of rock and soil aggregates by continuum-based discrete element method. Sci China E. 2005;48:95-106

52. Feng C, Li S, Liu X, Zhang Y. A semi-spring and semi-edge combined contact model in CDEM and its application to analysis of Jiweishan landslide. J Rock Mech Geotech Eng. 2014;6(1):26-35.

53. Ju Y, Wang Y, Chen J, Gao F, Wang J. Adaptive finite element-discrete element method for numerical analysis of the multistage hydrofracturing of horizontal wells in tight reservoirs considering pre-existing fractures, hydromechanical coupling, and leak-off effects. J Nat Gas Sci Eng. 2018;54:266-282.

54. Wang Y, Ju Y, Yang Y. Adaptive finite element-discrete element analysis for microseismic modelling of hydraulic fracture propagation of perforation in horizontal well considering pre-existing fractures. Shock Vib. 2018. https://doi.org/10.1155/2018/ 2748408.

55. Sheorey PR, Loui JP, Singh KB, Singh SK. Ground subsidence observations and a modified influence function method for complete subsidence prediction. Int $J$ Rock Mech Min Sci. 2000;37(5):801-818.

56. Kang H, Lou J, Gao F, Yang J, Li J. A physical and numerical investigation of sudden massive roof collapse during longwall coal retreat mining. Int $J$ Coal Geol. 2018;188:25-36.

57. Majdi A, Hassani FP, Nasiri MY. Prediction of the height of destressed zone above the mined panel roof in longwall coal mining. Int J Coal Geol. 2012;98:62-72.

58. Palchik V. Influence of physical characteristics of weak rock mass on height of caved zone over abandoned subsurface coal mines. Environ Geol. 2002;42(1):92-101.

59. Miao X, Cui X, Wang J, Xu J. The height of fractured water-conducting zone in undermined rock strata. Eng Geol. 2011;120(1-4):32-39.

60. Wang G, Wu M, Wang R, Xu H, Song X. Height of the mining-induced fractured zone above a coal face. Eng Geol. 2017;216:140-152.

61. State Administration of Quality and Technical Supervision. State Administration of Coal Mine Safety. Regulations on prevention and control of water in coal mines (In Chinese). Beijing: Coal Industry Press; 2009. 